\title{
Plant-wide Assessment of High-Pressure Membrane Contactors in Natural Gas Sweetening - Part I: Model Development
}

\author{
Ven Chian Quek ${ }^{\mathrm{a}, \mathrm{b}}$, Nilay Shah ${ }^{\mathrm{a}}$, Benoît Chachuata ${ }^{\mathrm{a}, *}$ \\ ${ }^{a}$ Centre for Process Systems Engineering, Department of Chemical Engineering, Imperial College London, UK \\ ${ }^{b}$ Group Research $\mathcal{F}$ Technology, PETRONAS, Kuala Lumpur, Malaysia
}

\begin{abstract}
This paper presents a predictive mathematical model of high-pressure membrane contactor, with a view to developing a plant-wide model of natural gas sweetening including amine regeneration. We build upon an existing model of high-pressure membrane contactor by Quek et al. [Chem Eng Res Des 132:1005-1019, 2018], which uses a combination of 1-d and 2-d mass-balance equations to predict the $\mathrm{CO}_{2}$ absorption flux and membrane wetting under lean solvent operation. For the first time, quantitative predictions of the $\mathrm{CO}_{2}$ absorption flux can be made under both lean and semi-lean operations. A 1-d energy balance that accounts for the solvent evaporative losses and the exothermic $\mathrm{CO}_{2}$ absorption into the amine is solved alongside the mass-balance equations, in order to predict the solvent temperature profile inside the contactor. The evaporative losses of water and amines can be quantified separately, as well as the absorptive losses of light hydrocarbons with the amine solvent. The model's predictive capability is tested against data from a lab-scale module and a pilot-scale module that is operated under industrially relevant conditions at a natural gas processing facility in Malaysia. A close agreement between model predictions and measurements of the $\mathrm{CO}_{2}$ absorption flux, solvent temperature profile, and hydrocarbon loss is observed for a wide range of gas and solvent flowrates and compositions, thereby validating the modeling assumptions. The contactor model is combined in a plant-wide model of natural gas sweetening in the companion paper, where it is used for process integration and analysis.
\end{abstract}

Keywords: membrane contactor, natural gas sweetening, high-pressure operation, solvent loss, hydrocarbon loss, experimental validation

\footnotetext{
${ }^{*}$ Corresponding author

Email address: b.chachuat@imperial.ac.uk (Benoît Chachuat)
} 


\section{Introduction}

Technology for $\mathrm{CO}_{2}$ capture based on physical and chemical principles include absorption, adsorption, cryogenic, carbonate looping, oxyfuel combustion, and membrane separation. By far the most widely adopted technology nowadays is chemical solvent absorption, using con-

5 ventional packed, spray or bubble column absorption towers. About $90 \%$ of the acid gas treating processes in operation use alkanoamines solvents, such as methylethanolamine (MEA), diethanolamine (DEA), and methyldiethanolamine (MDEA), which enable the removal of acid gases to trace levels [1, 2]. But conventional absorption towers have a high capital cost and a large physical footprint, and they are furthermore subject to flooding, channeling, foaming or

10 liquid entrainment during their operation [3]. Membrane technology has been applied since the 1980s for $\mathrm{CO}_{2}$ removal in large-scale applications due to their potential to reduce the footprint and the capital and operating costs [4]. But the usual gas separation membranes have a relatively low permeability, and their low selectivity can lead to large product loss.

A hybrid process combining the advantages of both conventional chemical absorption and membrane separation, called membrane contactor (MBC), has attracted significant interest over the past decade. The microporous membrane in MBC acts as a non-selective phase barrier, allowing the liquid and gas phases to be in contact with each other, yet without the dispersion of one phase into the other. This barrier prevents flooding or foaming issues from developing, and gives independent control over the gas and liquid flow rates, thereby facilitating the MBC

20 operation. Packaging into hollow-fiber membrane (HFM) modules offers a higher mass transfer area compared with conventional packed columns, giving $\mathrm{MBC}$ a high intensification potential [5, 6]. This modularity also empowers a more flexible design and scale-up. The effectiveness of $\mathrm{MBC}$ for both pre- and post-combustion $\mathrm{CO}_{2}$ capture, as well as natural gas (NG) sweetening and dehydration, is well established [4, 6-8]. For NG sweetening applications in particular, Hoff

25 and Svendsen [9] reported a 75\% reduction in volume using MBC compared to conventional packed columns. The technology has been embraced by industry too, with recent patents on acid gas removal from NG granted to Petroliam Nasional Berhad (PETRONAS) [10] and the Gas Technology Institute (GTI) [11].

However, MBC can present low mass-transfer rates, especially when the microporous mem-

so brane becomes wetted by the aqueous amine solvent. Wang et al. [12] reported that a change in the degree of wetting as small as $5 \%$ could lead to a $20 \%$ reduction in mass-transfer rate. Operating under the breakthrough pressure can, in principle, circumvent membrane wetting, but partial wetting is often the result of a nonuniform pore-size distribution in membranes, with bigger pores being more easily wetted. Apart from the membrane properties, factors that are known

35 to affect the degree of wetting include the inlet solvent pressure, temperature and composition, or the membrane fiber length and orientation [13-15]. Mathematical models accounting for convection, diffusion and reaction in the membrane fibers have proved instrumental in predicting the $\mathrm{CO}_{2}$ removal efficiency in $\mathrm{MBC}$, and understanding the occurrence and effect of membrane wetting [16]. In particular, models capable of quantitative predictions of the degree of membrane 40 wetting from a membrane's pore size distribution have been developed in atmospheric-pressure MBC [17, 18] and, more recently, in high-pressure MBC [19].

Thus far, comparatively little research has been conducted on the integration of an MBC unit with the downstream amine regeneration section. On top of existing MBC models, three key requirements to enable such process-wide modeling are the ability to predict: (i) $\mathrm{CO}_{2}$ removal 45 under both lean and semi-lean operations; (ii) solvent temperature profile and evaporative losses with the treated gas; and (iii) hydrocarbon losses by absorption in the amine solvent. Amine 
regeneration via $\mathrm{CO}_{2}$ desorption is an energy intensive process. A partial regeneration (semilean operation) could lead to large energy savings in comparison to the full regeneration (lean operation), but a semi-lean operation also reduces the $\mathrm{CO}_{2}$ absorption flux in the $\mathrm{MBC}$. Exploring this tradeoff would benefit from accurate predictions of $\mathrm{MBC}$ under both lean and semi-lean operation, which is currently lacking.

The effect of solvent evaporation on the MBC process performance has also been largely ignored to this day. The gradual loss of solvent to the treated gas in the MBC can modify the $\mathrm{CO}_{2}$ absorption rate in the $\mathrm{MBC}$, which requires regular water and amine make-up. Recent modeling work by Ghasem et al. [20] has quantified the amount of water evaporated from the solvent at various inlet solvent temperatures and under atmospheric pressure. But no research has accounted for evaporative amine losses in (atmospheric or high-pressure) MBC, to the best of our knowledge. Evaporation brings the solvent temperature down due to the latent heat of vaporization, while the evaporative losses increase with the solvent temperature. Predicting the net effect of the heat of reaction and latent heat on the MBC solvent temperature calls for detailed energy balance modeling, and verification against experimental data. Prediction of the temperature profile inside of the $\mathrm{MBC}$ may be used to refine the $\mathrm{CO}_{2}$ removal rate, detect the occurrence of a temperature bulge as in conventional $\mathrm{CO}_{2}$ absorption towers [21, 22], or even estimate the corrosion rate. The ability to predict the solvent temperature at the MBC outlet is also key to 65 designing the heat exchangers in the amine regeneration section.

In order to prevent the condensation of hydrocarbons in the $\mathrm{MBC}$, which could result in large hydrocarbon losses and cause downstream processing issues due to the presence of a second liquid phase, the usual guideline is to maintain the lean solution temperature at least $5{ }^{\circ} \mathrm{C}$ above the hydrocarbon dew point temperature of the treated gas [23, 24]. But a part of these hydro70 carbons will inevitably be absorbed by the amine solution [25-27] and end up in the waste acid gas stream, if they are not recovered. Although the solubility of light hydrocarbons, such as methane, ethane or propane, into the amine solvent is negligible at or near atmospheric pressure, it is known to increase by 10-30 fold when the pressure increases to 60 bar [25, 28]. To the best of our knowledge, the extent of hydrocarbon loss with the amine solvent has not been quantified 75 in any MBC model.

The main objective of this paper is the development of a predictive mathematical model of high-pressure MBC, which can be integrated into the plant-wide model of an MBC-based process for NG sweetening (cf. companion paper [29]). We build upon the high-pressure MBC model by Quek et al. [19], which uses a combination of 1-d and 2-d mass-balance equations to

80 predict the $\mathrm{CO}_{2}$ absorption flux under lean operation and various degrees of membrane wetting. An energy balance that accounts for the solvent evaporative losses and the exothermic $\mathrm{CO}_{2} \mathrm{ab}$ sorption into the amine is solved alongside the mass-balance equations, in order to predict the solvent temperature profile inside the MBC. For the first time, the evaporative losses of water and amines are quantified separately, which enables a more accurate estimation of the amount and

85 composition of solvent make-up. We also propose a simple, conservative approach to estimating the physical absorption of methane, ethane and propane in amine solvent at different temperature and pressure based on available solubility data. The predictive capability of this new model is tested against data from a lab-scale MBC module, as well as a pilot-scale MBC module operated under industrially relevant conditions at a natural gas processing facility in Malaysia. All of

90 the experiments were conducted in horizontally-oriented modules and with aqueous mixtures of MDEA and piperazine (PZ) as the chemical solvent. In comparison to Quek et al. [19], the MBC modules herein were packed with a new HFM, which has a smaller outer radius and is braided to increase the fiber length. 
The rest of the paper is organized as follows. The model of a horizontal counter-current 95 hollow-fiber MBC module is presented in Sec. 2. A description of both experimental set-ups, solubility property predictions for $\mathrm{CO}_{2}$ and light hydrocarbons, and computational methods is given in Sec. 3. Results of the experimental model verification are presented and discussed in Sec. 4, before concluding the paper in Sec. 5. In the companion paper [29], the MBC model is integrated into the plant-wide model of an MBC-based process for NG sweetening and used for 100 process integration and analysis.

\section{Predictive Modeling of Hollow-Fiber Membrane Contactor}

This section describes a comprehensive mathematical model of a high-pressure, hollow-fiber MBC module, as depicted on the left panel in Fig. 1. The $\mathrm{CO}_{2}$-rich natural gas mixture flows through the membrane fibers, while the amine solvent flows inside the shell, in a counter-current configuration. The gas mixture diffuses from the tube side through the fiber walls into the shell, where $\mathrm{CO}_{2}$ is chemically absorbed by the amine in order to enhance the removal rate.

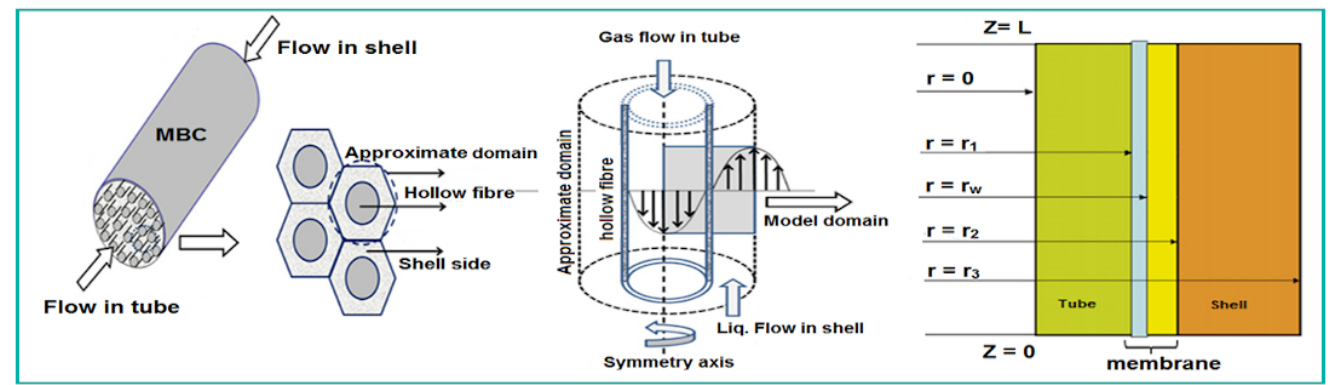

Figure 1: Modeling framework for a counter-current hollow-fiber MBC module. Left: cylindrical approximation around each fiber. Centre: single piece of hollow fiber. Right: spatial domains in MBC model.

\subsection{Background}

This subsection presents a summary of the MBC model developed by Quek et al. [19]. On exploiting symmetry, the spatial domain to model a piece of hollow fiber can be taken as $(r, z) \in$

${ }_{110}\left[0, r_{3}\right] \times[0, L]$, which is further partitioned into four subdomains as shown on the right panel in Fig. 11 (i) tube, $0 \leq r \leq r_{1}$; (ii) membrane-dry, $r_{1} \leq r \leq r_{\mathrm{w}}$; (iii) membrane wet, $r_{\mathrm{w}} \leq r \leq r_{2}$; and (iv) shell, $r_{2} \leq r \leq r_{3}$. Here, $r_{1}$ and $r_{2}$ represent the inner and outer radii of the fibers; and $r_{3}$ is the radius of a virtual fluid domain around each fiber [30], given by

$$
r_{3}=\frac{r_{2}}{\sqrt{\eta}}=\frac{r_{\mathrm{m}}}{\sqrt{n_{\mathrm{f}}}}
$$

with $\eta, r_{\mathrm{m}}$ and $n_{\mathrm{f}}$, the packing density, inner radius and number of fibers in the MBC module.

The conceptual variable $r_{\mathrm{w}}$ (Eq. 14), called wetted radius, represents the average depth of liquid in pores. It is defined via the wetting ratio $\omega$, which is the fraction of pore volume occupied by the liquid phase to the total pore volume (Eq. 13 . This representation assumes that pores with a diameter larger than the critical pore radius $\delta_{\mathrm{w}}$ are fully-wetted, whereas those with a diameter smaller than $\delta_{\mathrm{w}}$ are non-wetted. This critical pore radius itself depends on the membrane and 
120 solvent properties (Eq. 12) and the transmembrane pressure (Eq. 11). Notice that the non-wetted and fully-wetted modes of operation correspond to $r_{\mathrm{w}}=r_{2}$ and $r_{\mathrm{w}}=r_{1}$, respectively.

Steady-state mass balances in all of the phases are summarized below, with their corresponding boundary conditions. The gas phase in the lumen is described by a simple plug flow (Eq. 2), assuming uniform concentrations in each cross-section (Eq. 3) and neglecting the gas diffusivity

125 (Péclet $>10^{6}$ ) and pressure drops along the fiber axis. Real gas behavior is furthermore described using a compressibility factor correction. The liquid flow in the shell is laminar (Reynolds $<10$ ) and incompressible, with a fully developed velocity profile (Eq.7P) expressed using Happel's free surface model [30]. Axial diffusivity in the liquid phase (Eq. 6] is neglected (Péclet $>10^{7}$ ), as is the change in volume due to the reaction between $\mathrm{CO}_{2}$ and the solvent. The membrane proper-

130 ties are considered to be uniform along the fiber axis, including pore-size distribution, tortuosity, porosity, thickness, and hydrophobicity. Mass transfer inside the membrane is driven by radial diffusion only (Eqs. 4 \& 5), assuming immobile gas and liquid phases.

Boundary conditions are specified at both the gas and liquid inlets (Eqs. 17]\& 18), along with a no-flux condition at the liquid outlet (Eq. 19p). Concentration and flux continuity are expressed at the boundaries between the membrane and the gas or liquid phase (Eqs. 8 \& 15), whereas the liquid boundary condition (Eq. 16 follows from axi-symmetry. Mass transfer at the gasliquid interface is assumed to be at equilibrium, described by Henry's law (Eq. 9p, alongside flux conditions (Eq. 10). The dissolution of gas species other than $\mathrm{CO}_{2}$ into the liquid phase is neglected, as is the evaporation of the amine solvent. Estimation of these latter quantities is the focus of the developments in the following subsections.

Gas Phase, $z \in[0, L]$ :

$$
\begin{gathered}
\bar{v}_{\mathrm{g}}(z) \frac{\mathrm{d} \bar{C}_{\mathrm{CO}_{2}}}{\mathrm{~d} z}(z)=-2 \frac{\varepsilon D_{\mathrm{CO}_{2}, \mathrm{~g}}}{\tau r_{1}}\left[1-\frac{Z R T_{\mathrm{g}}}{P_{\mathrm{g}}}\right] \frac{\partial C_{\mathrm{CO}_{2}}}{\partial r}\left(r_{1}^{+}, z\right) \\
\frac{\mathrm{d} \bar{v}_{\mathrm{g}}}{\mathrm{d} z}(z)=-2 \frac{\varepsilon D_{\mathrm{CO}_{2}, \mathrm{~g}}}{\tau r_{1}} \frac{Z R T_{\mathrm{g}}}{P_{\mathrm{g}}} \frac{\partial C_{\mathrm{CO}_{2}}}{\partial r}\left(r_{1}^{+}, z\right)
\end{gathered}
$$

Membrane-Dry Phase, $(r, z) \in\left[r_{1}, r_{\mathrm{w}}(z)\right] \times[0, L]$ :

$$
0=\frac{\partial^{2} C_{\mathrm{CO}_{2}}}{\partial r^{2}}(r, z)+\frac{1}{r} \frac{\partial C_{\mathrm{CO}_{2}}}{\partial r}(r, z)
$$

Membrane-Wet Phase, $(r, z) \in\left[r_{\mathrm{w}}(z), r_{2}\right] \times[0, L]$ :

$$
0=\frac{\varepsilon}{\tau} D_{i, 1}\left[\frac{\partial^{2} C_{i}}{\partial r^{2}}(r, z)+\frac{1}{r} \frac{\partial C_{i}}{\partial r}(r, z)\right]+R_{i}\left(C_{i}(r, z)\right), \quad i \in\left\{\mathrm{CO}_{2}, \text { sol }\right\}
$$

Liquid Phase, $(r, z) \in\left[r_{2}, r_{3}\right] \times[0, L]$ :

$$
\begin{gathered}
v_{1}(r) \frac{\partial C_{i}}{\partial z}(r, z)=D_{i, 1}\left[\frac{\partial^{2} C_{i}}{\partial r^{2}}(r, z)+\frac{1}{r} \frac{\partial C_{i}}{\partial r}(r, z)+\frac{\partial^{2} C_{i}}{\partial z^{2}}(r, z)\right]+R_{i}\left(C_{i}(r, z)\right), \quad i \in\left\{\mathrm{CO}_{2}, \text { sol }\right\} \\
v_{1}(r)=2 \bar{v}_{1}\left(r_{3}^{2}-r_{2}^{2}\right) \frac{r_{3}^{2}-r_{2}^{2}+2 r_{3}^{2} \ln \left(\frac{r_{2}}{r_{3}}\right)}{4 r_{2}^{2} r_{3}^{2}-r_{2}^{4}-3 r_{3}^{4}-4 r_{3}^{4} \ln \left(\frac{r_{2}}{r_{3}}\right)}, \quad \bar{v}_{1}=\frac{F_{1}}{n_{\mathrm{f}} \pi r_{3}^{2}(1-\eta)}
\end{gathered}
$$

Gas-Membrane Interface, $r=r_{1}, z \in[0, L]$ :

$$
\bar{C}_{\mathrm{CO}_{2}}(z)=C_{\mathrm{CO}_{2}}\left(r_{1}^{+}, z\right)
$$


Gas-Liquid Interface, $r=r_{\mathrm{w}}(z), z \in[0, L]$ :

$$
\begin{aligned}
Z R T_{\mathrm{g}} C_{\mathrm{CO}_{2}}\left(r_{\mathrm{w}}^{-}(z), z\right) & =H_{\mathrm{CO}_{2}, 1} C_{\mathrm{CO}_{2}}\left(r_{\mathrm{w}}^{+}(z), z\right) \\
D_{\mathrm{CO}_{2}, \mathrm{~g}} \frac{\partial C_{\mathrm{CO}_{2}}}{\partial r}\left(r_{\mathrm{w}}^{-}(z), z\right) & =D_{\mathrm{CO}_{2}, 1} \frac{\partial C_{\mathrm{CO}_{2}}}{\partial r}\left(r_{\mathrm{w}}^{+}(z), z\right), \quad 0=\frac{\partial C_{\mathrm{sol}}}{\partial r}\left(r_{\mathrm{w}}^{+}(z), z\right) \\
\Delta P(z) & =P_{1}^{\text {out }}-P_{\mathrm{g}}+8 \mu_{1} \bar{v}_{1} \frac{r_{3}^{2}-r_{2}^{2}}{4 r_{2}^{2} r_{3}^{2}-r_{2}^{4}-3 r_{3}^{4}-4 r_{3}^{4} \ln \left(\frac{r_{2}}{r_{3}}\right)}(L-z) \\
\delta_{\mathrm{w}}(z) & =-\frac{2 \gamma \cos (\theta)}{\Delta P(z)} \\
\int_{\delta_{\mathrm{w}}(z)}^{\delta^{\max }} \delta^{2} \varphi(\delta) \mathrm{d} \delta & =\omega(z) \int_{0}^{\delta^{\max }} \delta^{2} \varphi(\delta) \mathrm{d} \delta \\
r_{\mathrm{w}}(z) & =r_{2}-\left[r_{2}-r_{1}\right] \omega(z)
\end{aligned}
$$

Liquid-Membrane Interface, $r=r_{2}, z \in[0, L]$ :

$$
C_{i}\left(r_{2}^{-}, z\right)=C_{i}\left(r_{2}^{+}, z\right), \quad \frac{\varepsilon}{\tau} \frac{\partial C_{i}}{\partial r}\left(r_{2}^{-}, z\right)=\frac{\partial C_{i}}{\partial r}\left(r_{2}^{+}, z\right), \quad i \in\left\{\mathrm{CO}_{2}, \mathrm{sol}\right\}
$$

Liquid Boundary, $r=r_{3}, z \in[0, L]$ :

$$
\frac{\partial C_{i}}{\partial r}\left(r_{3}, z\right)=0, \quad i \in\left\{\mathrm{CO}_{2}, \mathrm{sol}\right\}
$$

Gas Inlet, $z=L$ :

$$
\bar{v}_{\mathrm{g}}(L)=\frac{M_{\mathrm{g}}^{\mathrm{in}}}{n_{\mathrm{f}} \pi r_{1}^{2} \rho_{\mathrm{g}}}, \quad \bar{C}_{\mathrm{CO}_{2}}(L)=\frac{y_{\mathrm{CO}_{2}, \mathrm{~g}}^{\text {in }} P_{\mathrm{g}}}{Z R T_{\mathrm{g}}}
$$

Liquid Inlet, $z=0, r \in\left[r_{2}, r_{3}\right]$ :

$$
C_{\mathrm{sol}}(r, 0)=C_{\mathrm{sol}}^{\mathrm{in}}, \quad C_{\mathrm{CO}_{2}}(r, 0)=f_{\mathrm{CO}_{2}, 1}^{\mathrm{in}} C_{\mathrm{sol}}^{\text {in }}
$$

Liquid Outlet, $z=L, r \in\left[r_{2}, r_{3}\right]$ :

$$
\frac{\partial C_{i}}{\partial z}(r, L)=0
$$

\subsection{Modeling of Solvent Temperature and Evaporative Losses}

Temperature effects are an important aspect of $\mathrm{MBC}$ modeling. The solvent temperature rises as a result of the exothermic reactions between $\mathrm{CO}_{2}$ and the amines, which in turn modifies the thermophysical properties of the system, including the surface tension, diffusivity and absortivity of the solvent. Another temperature effect is the loss of solvent to the treated gas via evaporation, which lowers the solvent temperature due to the latent heat of vaporization.

Quek et al. [19] calculated the adiabatic temperature rise in the MBC caused by the heat of absorption, and they then applied a corresponding correction to the surface tension of the solvent. This approach helped to provide better predictions of the $\mathrm{CO}_{2}$ absorption fluxes measured in a 
pilot plant. However, it fails to describe the gradual increase in temperature along the MBC axis, and it does not account for evaporative solvent losses either.

We assume, as a first approximation, that the treated gas at the MBC outlet $(z=0)$ is saturated with solvent. Since the partial pressure of solvent in the treated gas is low, we use Raoult's law to predict the gas composition,

$$
y_{i, \mathrm{~g}}^{\text {out }}=y_{i, 1}^{\text {in }} \frac{P_{i}^{\text {sat }}}{P_{\mathrm{g}}}, \quad i \in\left\{\mathrm{H}_{2} \mathrm{O}, \mathrm{sol}\right\},
$$

with $P_{i}^{\text {sat }}$ the vapor pressure of pure component $i$ corresponding to the inlet solvent temperature. Clearly, this assumption may overpredict the solvent evaporation rate in case the gas residence time is shorter than it takes to reach equilibrium. But this analysis provides a worst-case scenario in terms of solvent evaporation, which will enable benchmarking the solvent losses in MBC against their counterpart losses in conventional packed columns. Notice that, since the gas inlet in a counter-flow MBC is solvent free, the rate of solvent loss is readily calculated as

$$
M_{i, \mathrm{~g}}^{\text {out }}=y_{i, \mathrm{~g}}^{\text {out }} M W_{i} \bar{v}_{\mathrm{g}}(0) n_{\mathrm{f}} \pi r_{1}^{2} \frac{P_{\mathrm{g}}}{Z R T_{\mathrm{g}}}=y_{i, 1}^{\text {in }} M W_{i} \bar{v}_{\mathrm{g}}(0) n_{\mathrm{f}} \pi r_{1}^{2} \frac{P_{i}^{\text {sat }}}{Z R T_{\mathrm{g}}}, \quad i \in\left\{\mathrm{H}_{2} \mathrm{O}, \text { sol }\right\} .
$$

In the formulation of a 1-d energy balance for the liquid in the shell compartment, we make the extra assumption that the heat losses from solvent evaporation take place at the liquid inlet. The rationale behind this assumption is that these heat losses are expected to be relatively small in comparison with the heat produced by the $\mathrm{CO}_{2}$ absorption reactions, and thus have little impact on the temperature profile inside the MBC; see Sec.4.1 for a verification and discussion. Under the assumption of a dry feed gas, the resulting temperature difference at the liquid inlet is then determined from the following balance,

$$
F_{1} \rho_{1} c_{P}\left(T_{1}^{\mathrm{in}}-T_{1}(0)\right)=\bar{v}_{\mathrm{g}}(0) n_{\mathrm{f}} \pi r_{1}^{2} \sum_{i \in\left\{\mathrm{H}_{2} \mathrm{O}, \mathrm{sol}\right\}} y_{i, 1}^{\text {in }} \frac{P_{i}^{\text {sat }}}{Z R T_{\mathrm{g}}} \Delta H_{i}^{\mathrm{vap}},
$$

where $\Delta H_{i}^{\mathrm{vap}}$ stands for the latent heat of vaporization of species $i$; and $c_{P}$, the specific heat capacity of the solvent.

We describe the liquid temperature in the shell using a simple plug flow analogy, whereby the temperature is taken uniform in each cross-section and the thermal diffusivity in the axial direction is neglected (Péclet $>10^{4}$ ). The following 1-d energy balance accounts for the sole heat generated by the $\mathrm{CO}_{2}$ absorption reactions and considers adiabatic conditions,

$$
F_{1} \rho_{1} c_{P} \frac{\mathrm{d} T_{1}}{\mathrm{~d} z}(z)=n_{\mathrm{f}} \pi r_{1}^{2} \frac{\partial\left(\bar{v}_{\mathrm{g}} \bar{C}_{\mathrm{CO}_{2}}\right)}{\partial z}(z) \Delta H^{\mathrm{rxn}}
$$

where $\Delta H^{\mathrm{rxn}}$ is the enthalpy of reaction. Overall, this $1-\mathrm{d}$ energy balance (Eq. 23 ) is solved alongside the corresponding 2-d mass-balance (Eq. 6). Thermophysical quantities in the liquid phase, including the Henry's constant, contact angle, diffusivities and reaction rates, are furthermore calculated as a function of $T_{1}(z)$ along the MBC axis.

\subsection{Modeling of Hydrocarbon Losses}

We use a similar approach to estimating hydrocarbon losses as for the solvent losses. Specifically, we assume that the solvent is saturated with light hydrocarbons at the MBC liquid outlet 
Table 1: Operational variables and ranges in the lab and pilot experimental setups.

\begin{tabular}{lcc}
\hline Variable & Lab setup & Pilot setup \\
\hline Gas feed & $\mathrm{N}_{2}: \mathrm{CO}_{2}$ & $\mathrm{NG}$ \\
$\mathrm{CO}_{2}$ inlet, $y_{\mathrm{CO}_{2}, \mathrm{~g}}^{\text {in }}(\mathrm{mol} \%)$ & $20-24$ & $5-18$ \\
$\mathrm{MDEA} / \mathrm{PZ}$ inlet, $w_{\text {sol, } 1}^{\text {in }}(\mathrm{wt} \%)$ & $37 / 6$ & $39 / 5$ \\
Inlet gas pressure, $P_{\mathrm{g}}^{\text {in }}(\mathrm{kPa})$ & 5400 & 5400 \\
Outlet liquid pressure, $P_{1}^{\text {out }}(\mathrm{kPa})$ & 5430 & 5430 \\
Inlet gas flowrate, $M_{\mathrm{g}}^{\text {in }}\left(\mathrm{kg} \mathrm{h}{ }^{-1}\right)$ & $2-3$ & $50-75$ \\
Inlet liquid flowrate, $F_{1}^{\text {in }}\left(\mathrm{L} \mathrm{h}^{-1}\right)$ & $8-10$ & $175-270$ \\
Inlet gas temperature, $T_{\mathrm{g}}^{\text {in }}(\mathrm{K})$ & 293 & 298 \\
Inlet liquid temperature, $T_{1}^{\text {in }}(\mathrm{K})$ & $310-313$ & $303-308$ \\
$\mathrm{CO}_{2}$ loading in solvent, $f_{\mathrm{CO}_{2}, 1}^{\text {in }}\left(\mathrm{mol} \mathrm{mol}^{-1}\right)$ & $0.01-0.23$ & $0.01-0.23$ \\
\hline
\end{tabular}

$(z=L)$, and we rely on Henry's law to estimate their concentrations as

$$
C_{i, 1}^{\text {out }}=\frac{y_{i, \mathrm{~g}}^{\text {in }} P_{g}}{H_{i, 1}}, \quad i \in\left\{\mathrm{CH}_{4}, \mathrm{C}_{2} \mathrm{H}_{6}, \mathrm{C}_{3} \mathrm{H}_{8}\right\},
$$

\section{Material and Methods}

\subsection{Experimental Setups}

The lab-scale module experiments were conducted with a binary gas mixture of $\mathrm{N}_{2}: \mathrm{CO}_{2}$ at while the pilot module was operated under industrially relevant operating conditions at 54 bar as part of a natural gas processing plant in Malaysia. The scaling factor between the lab and pilot setups is about 40 in terms of membrane area. In both cases, aqueous mixtures of MDEA and PZ were used as the chemical solvent. The lab and pilot setups are depicted in Figs. 2 and 3 , and the corresponding operating conditions are summarized in Table 1 . Following the recommendations by Quek et al. [19], the MBC modules are oriented horizontally in order to mitigate membrane wetting by avoiding the effect of the liquid static head.

Lab-Scale MBC Module. Pressurized gas cylinders were used to supply the (dry) mixture of $\mathrm{N}_{2}: \mathrm{CO}_{2}$ at the tube side of the module at 54 bar, while the lean amine solvent was pumped into the shell side, in a counter-current configuration. A transmembrane pressure $\Delta P \geq 30 \mathrm{kPa}$ was maintained along the fibers to prevent gas bubbling [28]. The gas and solvent feed flowrates were 


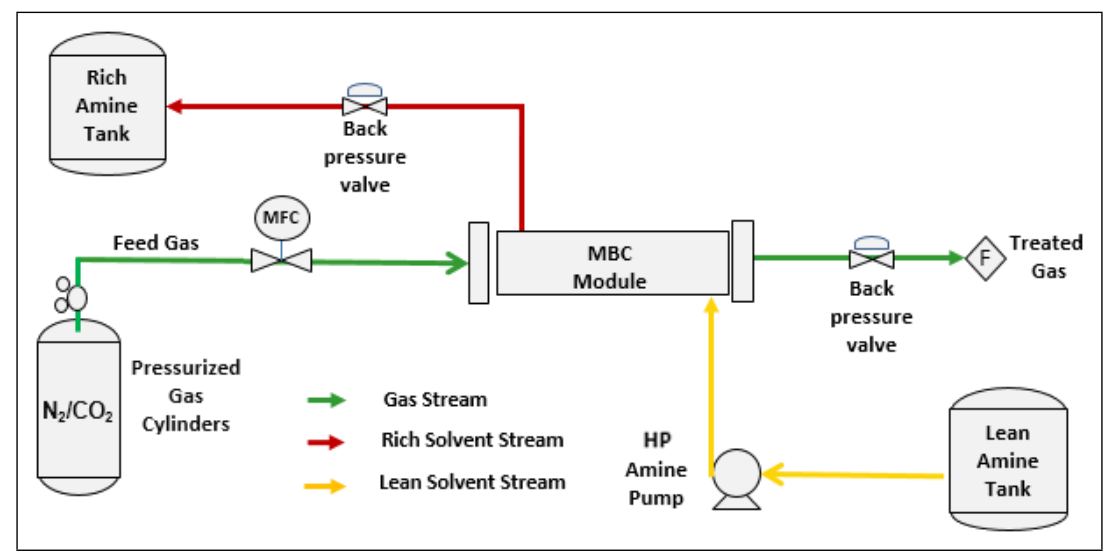

Figure 2: Schematic of the lab-scale setup for $\mathrm{CO}_{2}$ removal using high pressure MBC.

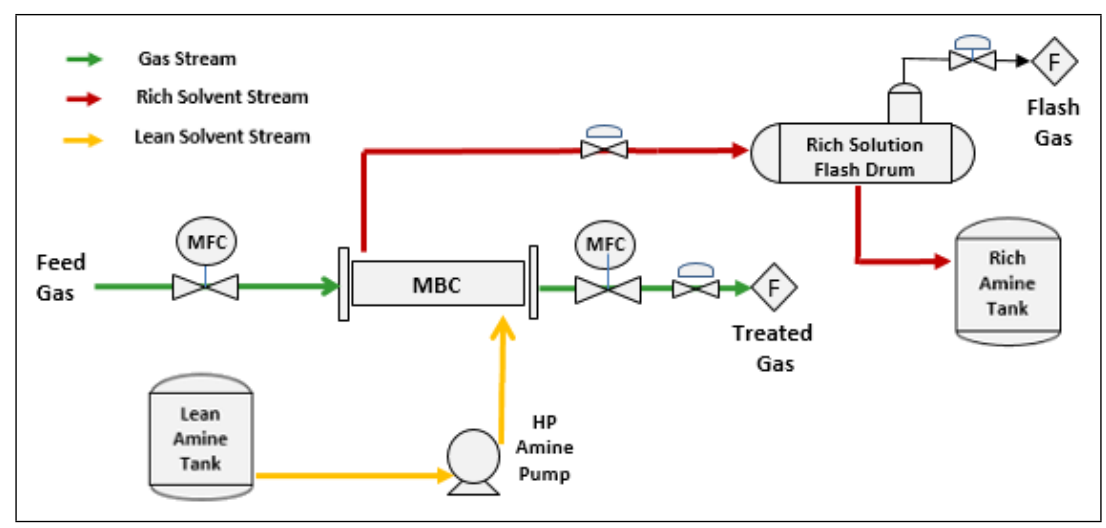

Figure 3: Schematic of the pilot-plant setup for $\mathrm{CO}_{2}$ removal using high pressure MBC.

controlled using a mass flow controller (MFC) and pump stroke, respectively. The compositions of the feed gas and treated gas were analyzed and recorded using gas chromatography (GC7900, Techcomp (Holdings) Ltd.), after the system had reached steady state as detected by a constant $\mathrm{CO}_{2}$ composition in the outlet gas stream of the module. The treated gas from the MBC module was then depressurized and vented to a safe location. The inlet and outlet solvent temperatures were measured using standard thermocouples. The solvent temperature along the MBC axis was also measured using a fully-calibrated Infrared Thermometer with built-in laser pointer (IR400, Extech).

Pilot-Scale MBC Module. The $\mathrm{CO}_{2}$-rich natural gas with up to $18 \mathrm{~mol} \% \mathrm{CO}_{2}$ was produced by blending pure $\mathrm{CO}_{2}$ from pressurized gas cylinders into the NG feed stream, and fed at the tube side of the module at 54 bar. Any water and hydrocarbon liquids were removed from the feed gas using a liquid-Gas coalescer. The lean amine was pumped into the shell side, in a counter-current configuration, by maintaining the transmembrane pressure above $30 \mathrm{kPa}$ along the fibers. The system was run with a constant set of operational variables until a steady state was reached. The gas and liquid feed flowrates were controlled using a mass flow controller and a 
Table 2: Properties of hollow-fiber membrane (top part) and module specifications (bottom part).

\begin{tabular}{lcc}
\hline Property & Value & Source \\
\hline Fiber length, $L(\mathrm{~m})$ & 2.3 & DICP $^{\mathrm{a}}$ \\
Fiber inner radius, $r_{1}(\mu \mathrm{m})$ & 225 & DICP $^{\mathrm{a}}$ \\
Fiber outer radius, $r_{2}(\mu \mathrm{m})$ & 550 & DICP $^{\mathrm{a}}$ \\
Membrane porosity, $\varepsilon(-)$ & 0.41 & DICP $^{\mathrm{a}}$ \\
Membrane tortuosity, $\tau(-)$ & 6.1 & Eq. $[26)$ \\
Maximal pore radius, $\delta^{\mathrm{max}}(\mu \mathrm{m})$ & 0.18 & DICP \\
Mean pore radius, $\mu_{\delta}(\mu \mathrm{m})$ & 0.06 & Eq. $[27)$ \\
Pore standard deviation, $\sigma_{\delta}(\mu \mathrm{m})$ & 0.24 & Eq. $(27)$ \\
Contact angle, $\theta\left(^{\circ}\right)$ & 92.4 & DICP \\
\hline \hline Parameter & Lab setup & Pilot setup \\
\hline Packing density, $\eta(-)$ & 0.40 & 0.38 \\
Module inner radius, $r_{\mathrm{m}}(\mathrm{mm})$ & 12.5 & 115 \\
Membrane area, $A_{\mathrm{m}}\left(\mathrm{m}^{2}\right)$ & 1.67 & 68 \\
Number of fibers, $n_{\mathrm{f}}$ & 209 & 8,400 \\
\hline
\end{tabular}

${ }^{a}$ the Dalian Institute of Chemical Physics.

pump stroke, respectively. The flowrate of the treated gas at the MBC outlet was measured with a mass flowmeter, before sending it to the flare header. The enriched amine solvent collected from the module shell outlet was directed to a flash drum operating at 9.1 bar, before sending the the flashed gases to the flare header. The gas composition at both inlet and outlet of the MBC module and at the outlet of the flash drum were analyzed using gas chromatography (PGC1000, $\mathrm{ABB}$ ), and the corresponding gas flowrates were measured. Samples were also taken at the MBC liquid inlet and the flash drum liquid outlet to monitor the amine concentration and $\mathrm{CO}_{2}$ loading in the solvent.

\subsection{Membrane and Module Characterization}

The high-pressure MBC modules were packed with hydrophobic, polytetrafluoroethylene (PTFE) hollow fiber. In comparison to our previous work [19], the fibers were thinner and had a smaller outer radius. Braiding was also used to increase the fiber length by about $15 \%$. Because of operational restrictions on the maximal gas flowrate in the pilot setup $\left(75 \mathrm{~kg} \mathrm{~h}^{-1}\right)$, the packing density and specific membrane area were artificially reduced by inserting a steel tube at the center of the pilot-scale module-otherwise, the $\mathrm{CO}_{2}$ removal efficiency would be close to $100 \%$ in all of the experiments with the new HFM.

Table 2 reports the main characteristics of these membranes, alongside design properties of the MBC modules used for lab- and pilot-scale testing. A first approximation of the membrane tortuosity was determined from the correlation

$$
\tau=\frac{(2-\varepsilon)^{2}}{\varepsilon}
$$

which was shown by Iversen et al. [31] to closely predict the experimental tortuosities for a range of membrane manufactured by stretching methods (such as polypropylene or PTFE). Scanning 

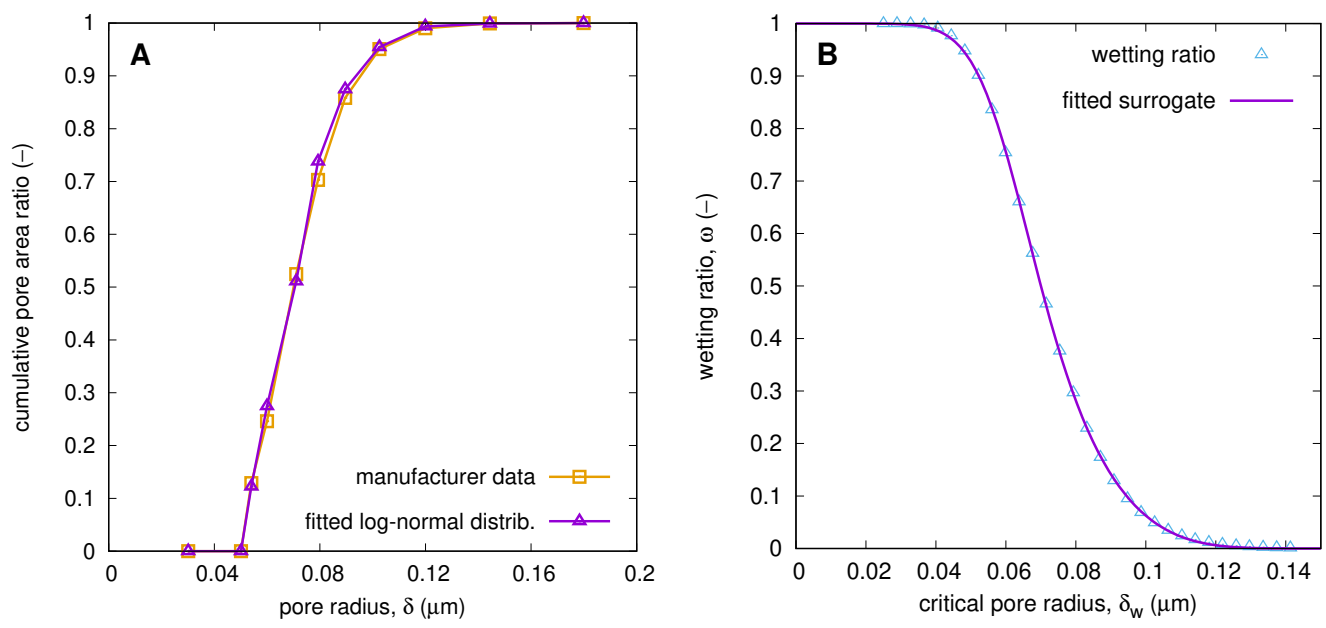

C

\begin{tabular}{cccc}
\hline$a_{0}$ & $a_{1}$ & $a_{2}$ & $a_{3}$ \\
9.03 & -17.21 & 11.22 & -2.94 \\
\hline
\end{tabular}

Figure 4: A: Comparison of cumulative pore area ratio distribution based on a log-normal pore size distribution (Eq. 27 using the parameters in Table 2 B: Comparison between wetting ratio model (Eq. 13 and fitted surrogate (Eq. 28) in terms of the critical pore radius; C: Fitted regression coefficients in wetting ratio surrogate (Eq. 28.

electron microscopy (SEM) furthermore confirmed the spongy structure of the PTFE membrane, which is in agreement with the large turtuosity value in Table 2.

Pore-size distribution (PSD) data from the manufacturer were used to fit the following lognormal distribution [13, 32]

$$
\varphi(\delta)=\frac{1}{\sqrt{2 \pi \ln \left(1+\sigma_{\delta}^{2}\right)} \mu_{\delta}} \exp \left(-\frac{\left(\ln \delta-\ln \mu_{\delta}\right)^{2}\left(1+\sigma_{\delta}^{2}\right)}{2 \ln \left(1+\sigma_{\delta}^{2}\right)}\right),
$$

where $\mu_{\delta}$ and $\sigma_{\delta}$ stand for the mean pore radius and standard deviation, respectively. Excellent agreement of this distribution with the PSD data is seen on the panel A of Fig. 4 . A surrogate relationship for the wetting ratio $\omega$ (Eq. 13) as a function of the critical pore radius $\delta_{\mathrm{w}}$ in the range $\left[0, \delta^{\max }\right]$ was then regressed in the form of

$$
\omega\left(\delta_{\mathrm{w}}\right)=\frac{1}{2}+\frac{1}{2} \tanh \left(a_{0}+a_{1} \frac{\delta_{\mathrm{w}}}{\mu_{\delta}}+a_{2}\left(\frac{\delta_{\mathrm{w}}}{\mu_{\delta}}\right)^{2}+a_{3}\left(\frac{\delta_{\mathrm{w}}}{\mu_{\delta}}\right)^{3}\right) .
$$

250 The surrogate fit can be seen on the panel B of Fig. 4, with the coefficients $a_{0}, \ldots, a_{3}$ given on the panel C.

For verification purposes, the local mass transfer coefficient in the pores can be estimated as $k_{\mathrm{m}}=\frac{D_{\mathrm{m}} \varepsilon}{\tau\left[r_{2}-r_{1}\right]}$ [33]. The resulting $k_{\mathrm{m}}$ values of $2.7 \times 10^{-4} \mathrm{~m} \mathrm{~s}^{-1}$ and $4.9 \times 10^{-6} \mathrm{~m} \mathrm{~s}^{-1}$ are typical of dry and wet membranes in $\mathrm{MBC}$, respectively. 


\subsection{Thermo-Physical, Transport, and Reaction Kinetic Data}

The ability to predict $\mathrm{CO}_{2}$ solubility in lean or semi-lean amine is paramount to accurately quantify solvent evaporative losses (Sec. 2.2) and is discussed first. Predicting the solubility of light hydrocarbons likewise, which is key to quantify hydrocarbon losses with the solvent (Sec. 2.3) is also discussed. For completeness, other temperature-dependent expressions for (i)

260 the macroscopic reaction rates of $\mathrm{CO}_{2}$ with MDEA and $\mathrm{PZ}$, and (ii) the diffusivity coefficients of the various species in gas or liquid mixtures are reported in the appendix. The rest of the thermo-physical and transport parameters were obtained form the property packages Advanced Peng-Robinson and UNIQUAC-RK for the gas and liquid phases, respectively.

Prediction of $\mathrm{CO}_{2}$ Solubility in Amine Solvent. Measurements of $\mathrm{N}_{2} \mathrm{O}$ solubility in aqueous amine with $50 \mathrm{wt} \%$ MDEA were gathered from the work of Park and Sandall [34]. The following polynomial surrogate was regressed on this data set, for $\mathrm{CO}_{2}$ loadings and temperatures in the range of $0-0.5 \mathrm{~mol} \mathrm{~mol}^{-1}$ and $295-353 \mathrm{~K}$ :

$$
H_{\mathrm{N}_{2} \mathrm{O}, 1}=\alpha_{\mathrm{CO}_{2}}^{0}+\alpha_{\mathrm{CO}_{2}}^{1} f_{\mathrm{CO}_{2}, 1}+\alpha_{\mathrm{CO}_{2}}^{2} T_{1}+\alpha_{\mathrm{CO}_{2}}^{3}\left(f_{\mathrm{CO}_{2}, 1}\right)^{2}+\alpha_{\mathrm{CO}_{2}}^{4}\left(T_{1}\right)^{2}+\alpha_{\mathrm{CO}_{2}}^{5} f_{\mathrm{CO}_{2}, 1} T_{1} \text {, }
$$

where we neglect the effect of pressure on Henry's constant, and assume that PZ behaves like MDEA. The comparison in Fig. 5( (panel A) shows excellent agreement between the experimental and predicted Henry's constants, with an absolute average deviation (AAD) of $1.8 \%$ and most predictions within $\pm 5 \%$. The corresponding regression coefficients, $\alpha_{\mathrm{CO}_{2}}^{k}$ are reported on the panel C. The semi-empirical correlation of the excess Henry's coefficient of $\mathrm{N}_{2} \mathrm{O}$ in lean amine by Bensetiti et al. [35] (panel B), which we used in our previous work [19], underestimates the $\mathrm{CO}_{2}$ solubility in amine by over $20 \%$ compared to the regressed Henry's constant, and this mismatch increases beyond $30 \%$ at high $\mathrm{CO}_{2}$ loading.

Prediction of Light Hydrocarbon Solubility in Amine Solvent. Measurements of methane, ethane and propane solubility in water and in aqueous amine with $50 \mathrm{wt} \%$ MDEA were gathered from the work of Carroll et al. [25]. The following polynomial expression was regressed on each data set, for pressures and temperatures in the range of 300-345 $\mathrm{K}$ and 48-72 bar:

$$
\begin{array}{r}
H_{i, 1}=\alpha_{i}^{0}+\alpha_{i}^{1} w_{\text {MDEA }, 1}+\alpha_{i}^{2} T_{1}+\alpha_{i}^{3} P_{1}+\alpha_{i}^{4} w_{\text {MDEA }, 1} T_{1}+\alpha_{i}^{5} w_{\text {MDEA }, 1} P_{1}+\alpha_{i}^{6} T_{1} P_{1}, \\
i \in\left\{\mathrm{CH}_{4}, \mathrm{C}_{2} \mathrm{H}_{6}, \mathrm{C}_{3} \mathrm{H}_{8}\right\},
\end{array}
$$

where we neglect the effect of $\mathrm{CO}_{2}$ loading in the aqueous amine solvent. The comparison in Fig. 6 (panels A-C) shows that the predicted and experimental Henry's constants are in good agreement, with most predictions within $\pm 5 \%$. The regression coefficients, $\alpha_{i}^{k}$ in each regression are reported on the panel $\mathrm{D}$, along with the corresponding absolute average deviations (AAD). The predicted Henry's constants feed into the analysis of hydrocarbon losses (Eq.25.

\section{3.4. Model implementation and numerical solution}

The mixed set of algebraic, ordinary differential and partial differential equations was implemented in the gPROMS $^{\circledR}$ modelling language [36], using ModelBuilder v5.1. A second-order centered finite difference scheme was used to discretize the differential equations, after a rescaling of the radial dimension in the partial differential equations in order for the dry and wet membrane subdomains to be rectangular. A uniform mesh grid consisting of 70 elements was chosen to perform the simulations herein, which provides solutions within $1 \%$ of finer discretizations, while retaining computational tractability. With this discretization approach, the steady-state simulation of an MBC module takes a few minutes to complete on a desktop computer running Windows 7 with Intel ${ }^{\circledR}$ Core $^{\mathrm{TM}} \mathrm{i} 7-4790 \mathrm{CPU}$ at $3.60 \mathrm{GHz}$ and $32 \mathrm{~GB}$ of RAM. 

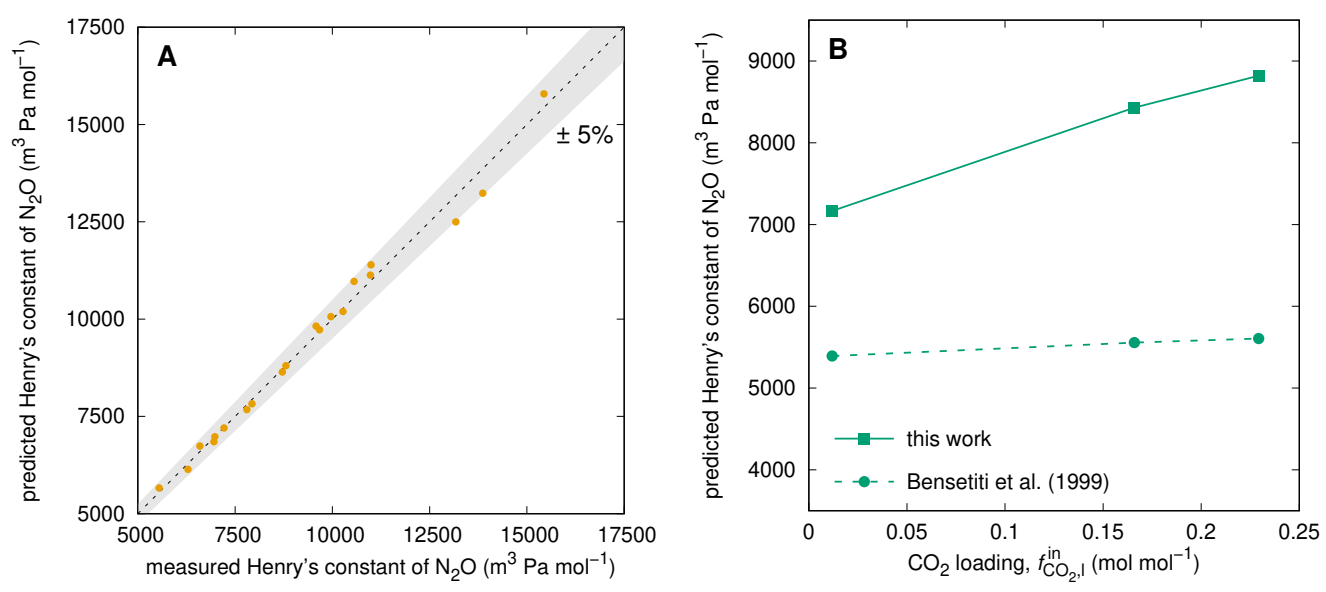

C

\begin{tabular}{ccccccc}
\hline$\alpha_{\mathrm{CO}_{2}}^{0}$ & $\alpha_{\mathrm{CO}_{2}}^{1}$ & $\alpha_{\mathrm{CO}_{2}}^{2}$ & $\alpha_{\mathrm{CO}_{2}}^{3}$ & $\alpha_{\mathrm{CO}_{2}}^{4}$ & $\alpha_{\mathrm{CO}_{2}}^{5}$ & $\mathrm{AAD}$ \\
$-3.30 \times 10^{4}$ & $-3.79 \times 10^{4}$ & $1.70 \times 10^{2}$ & $-4.37 \times 10^{3}$ & $-1.34 \times 10^{-1}$ & $1.45 \times 10^{2}$ & $1.9 \%$ \\
\hline
\end{tabular}

Figure 5: A: Predicted Henry's constant of $\mathrm{N}_{2} \mathrm{O}$ in $50 \mathrm{wt} \%$ aqueous MDEA (Eq. 29 against measurements from Park and Sandall [34]; B: Comparison of Henry's constant prediction (Eq. 29] to the semi-empirical correlation of Bensetiti et al. [35] at various $\mathrm{CO}_{2}$ loadings; $\mathbf{C}$ : Regression coefficients and statistics.

\section{Results and Discussion}

A comparison of the MBC model against lab and pilot experiments was presented in Quek et al. [19], in the case of lean operation only. Herein, we test the predictive capability of the model under semi-lean operation (Secs. 4.1 \& 4.2. The comparisons are conducted against experimental data measured on both the lab- and pilot-scales modules, in terms of the $\mathrm{CO}_{2}$ absorption flux, $\Phi$ given by

$$
\Phi=\frac{n_{\mathrm{f}} \pi r_{1}^{2}}{A_{\mathrm{m}}}\left[\bar{v}_{\mathrm{g}}(L) \bar{C}_{\mathrm{CO}_{2}}(L)-\bar{v}_{\mathrm{g}}(0) \bar{C}_{\mathrm{CO}_{2}}(0)\right] .
$$

Notice that error bars are not reported for experimental fluxes as the measured flowrates and gas compositions were averaged over several hours after reaching a steady-state operation. We also verify the temperature predictions against temperature measurements inside the lab-scale module under semi-lean operation. A third experimental verification is made regarding the absorptive losses of light hydrocarbons with the solvent in the pilot plant (Sec. 4.3). Lastly, we conduct a final model-based assessment on the evaporative losses of amine solvent (Sec.4.4.

\subsection{Experimental Model Verification: Lab Setup}

Comparisons between measured and predicted $\mathrm{CO}_{2}$ absorption fluxes in the lab-scale module are presented in Fig. $7 \mathrm{~A}-\mathrm{C}$, for different $\mathrm{CO}_{2}$ loadings and flowrates of amine solvent and gas flowrates as specified in the table insert. The flux predictions obtained using the regressed Henry's constant in Eq. 29) are in excellent agreement with the experimental fluxes. By contrast, the fluxes computed using the semi-empirical correlation of Bensetiti et al. [35] (Fig. 53) 

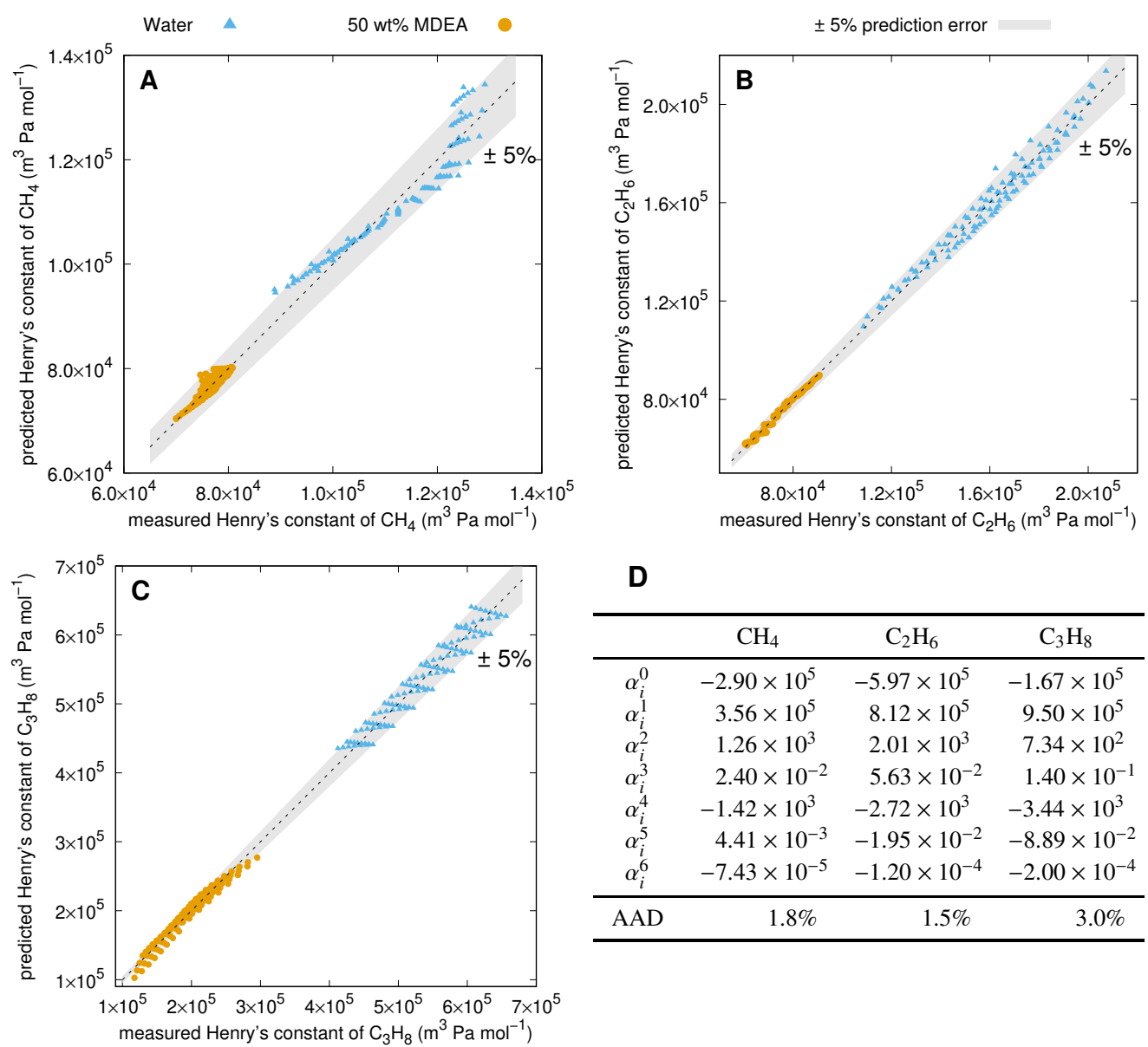

D

\begin{tabular}{cccc}
\hline & \multicolumn{1}{c}{$\mathrm{CH}_{4}$} & \multicolumn{1}{c}{$\mathrm{C}_{2} \mathrm{H}_{6}$} & \multicolumn{1}{c}{$\mathrm{C}_{3} \mathrm{H}_{8}$} \\
\hline$\alpha_{i}^{0}$ & $-2.90 \times 10^{5}$ & $-5.97 \times 10^{5}$ & $-1.67 \times 10^{5}$ \\
$\alpha_{i}^{1}$ & $3.56 \times 10^{5}$ & $8.12 \times 10^{5}$ & $9.50 \times 10^{5}$ \\
$\alpha_{i}^{2}$ & $1.26 \times 10^{3}$ & $2.01 \times 10^{3}$ & $7.34 \times 10^{2}$ \\
$\alpha_{i}^{3}$ & $2.40 \times 10^{-2}$ & $5.63 \times 10^{-2}$ & $1.40 \times 10^{-1}$ \\
$\alpha_{i}^{4}$ & $-1.42 \times 10^{3}$ & $-2.72 \times 10^{3}$ & $-3.44 \times 10^{3}$ \\
$\alpha_{i}^{5}$ & $4.41 \times 10^{-3}$ & $-1.95 \times 10^{-2}$ & $-8.89 \times 10^{-2}$ \\
$\alpha_{i}^{6}$ & $-7.43 \times 10^{-5}$ & $-1.20 \times 10^{-4}$ & $-2.00 \times 10^{-4}$ \\
\hline $\mathrm{AAD}$ & $1.8 \%$ & $1.5 \%$ & $3.0 \%$ \\
\hline
\end{tabular}

Figure 6: Predicted Henry's constant using Eq. 30] against solubility measurements in water (orange points) and $50 \mathrm{wt} \%$ aqueous MDEA (blue points) from Carroll et al. [25]. A: Methane; B: Ethane; C: Propane; D: Regression coefficients and statistics.

present a systematic overestimation by up to $10 \%$. Recall that this latter correlation does not account for the reduction in $\mathrm{CO}_{2}$ solubility in semi-lean amine solvents. Such an overestimation indicates that the mass transfer at the gas-liquid interface is limiting for the $\mathrm{CO}_{2}$ absorption flux under semi-lean operation, and clearly shows the need to model the effect of $\mathrm{CO}_{2}$ loading in amine solvent on the $\mathrm{CO}_{2}$ solubility for accurate predictions of the $\mathrm{CO}_{2}$ absorption fluxes in $\mathrm{MBC}$. It remains that both predictions are in close agreement under lean condition (first experimental point on Fig. 77A), despite a $25 \%$ difference in their respective Henry's constants (Fig. 53)

${ }_{320}$ This observation - which was also made in the pilot-scale module (Figs. 5D-E) - suggests that the absorption flux is no longer limited by the $\mathrm{CO}_{2}$ solubility under lean operation, i.e. other mass-transfer limitations such as diffusion in the solvent bulk become more prominent.

The MBC model correctly predicts the reduction in $\mathrm{CO}_{2}$ absorption flux at higher $\mathrm{CO}_{2}$ solvent loading (Fig. 7A). This trend results from a combination of direct and indirect effects as the ${ }_{325} \mathrm{CO}_{2}$ loading in the solvent increases: (i) less free amine available to react with $\mathrm{CO}_{2}$; (ii) a lower 

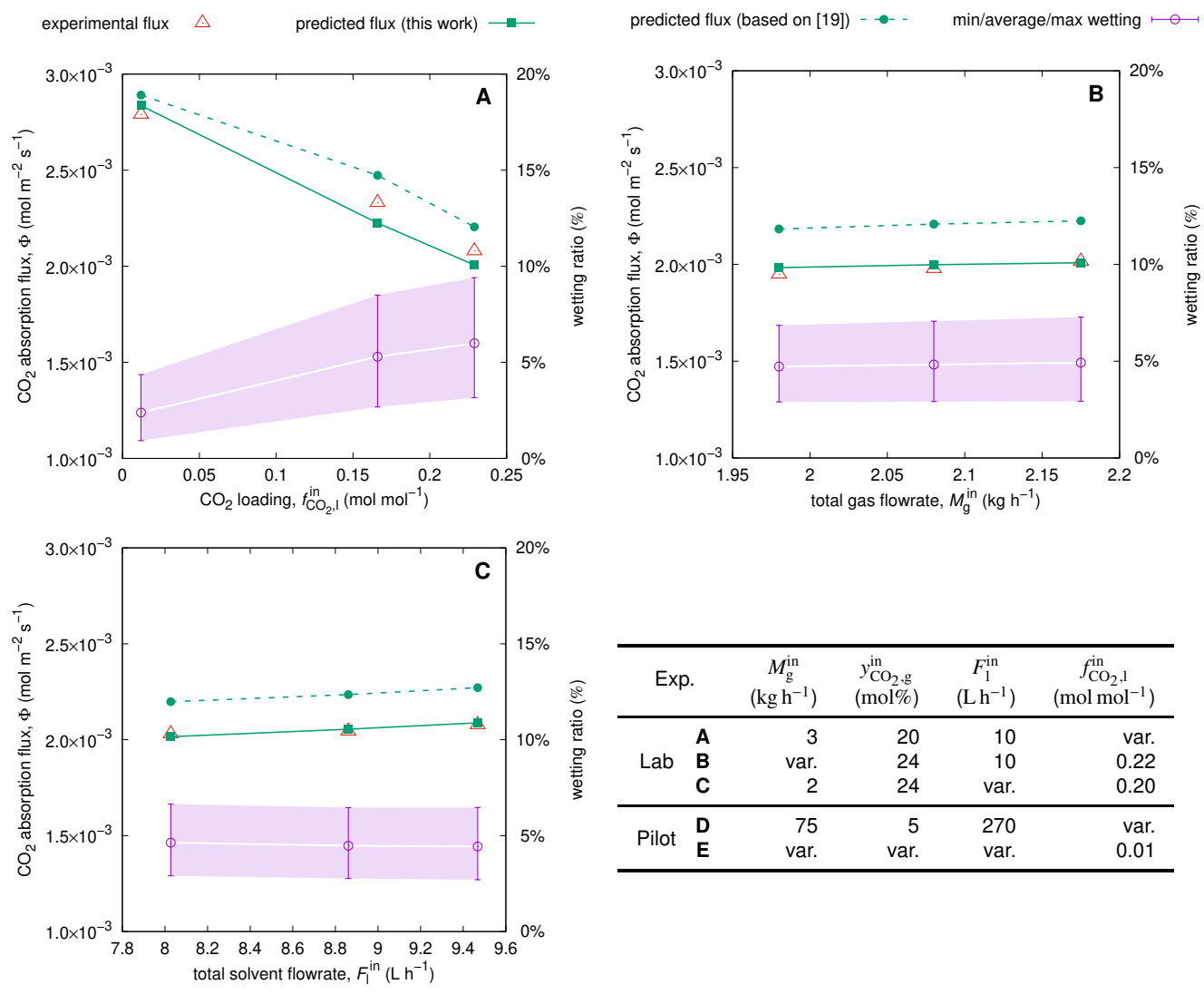

\begin{tabular}{rrrrrr}
\hline Exp. & $\begin{array}{c}M_{\mathrm{g}}^{\text {in }} \\
\left(\mathrm{kg} \mathrm{h}^{-1}\right)\end{array}$ & $\begin{array}{c}y_{\mathrm{CO}_{2}, \mathrm{~g}}^{\text {in }} \\
(\mathrm{mol} \%)\end{array}$ & $\begin{array}{c}F_{1}^{\text {in }} \\
\left(\mathrm{L} \mathrm{h}^{-1}\right)\end{array}$ & $\begin{array}{c}f_{\mathrm{CO}_{2}, 1}^{\text {in }} \\
\left(\mathrm{mol} \mathrm{mol}^{-1}\right)\end{array}$ \\
\cline { 2 - 7 } & $\mathbf{A}$ & 3 & 20 & 10 & var. \\
\hline \multirow{2}{*}{ Lab } & $\mathbf{B}$ & var. & 24 & 10 & 0.22 \\
& $\mathbf{C}$ & 2 & 24 & var. & 0.20 \\
\hline & $\mathbf{D}$ & 75 & 5 & 270 & var. \\
& $\mathbf{E}$ & var. & var. & var. & 0.01 \\
\hline
\end{tabular}
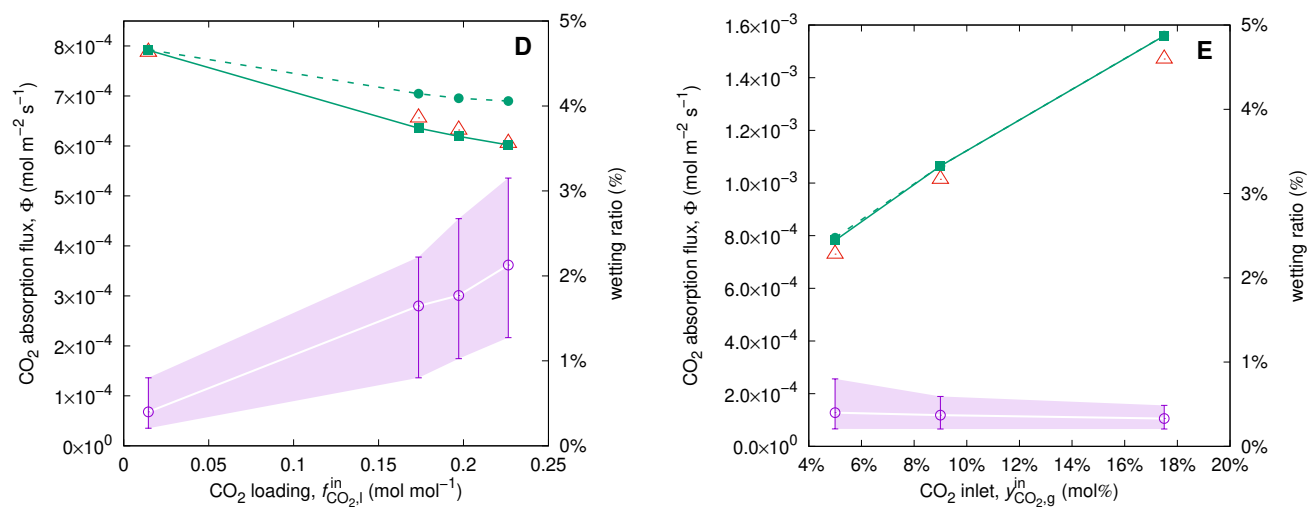

Figure 7: Comparison of predicted $\mathrm{CO}_{2}$ absorption fluxes against experimental data from the lab setup (A-C) and pilot setup (D-E), and corresponding membrane wetting predictions. A: effect of $\mathrm{CO}_{2}$ loading; $\mathbf{B}$ : effect of gas flowrate; C: effect of solvent liquid flowrate; D: effect of $\mathrm{CO}_{2}$; $\mathbf{E}$ : combined effect of gas flowrate, gas composition and solvent flowrate. The table insert summarizes the operational parameters explored during the experiments. 


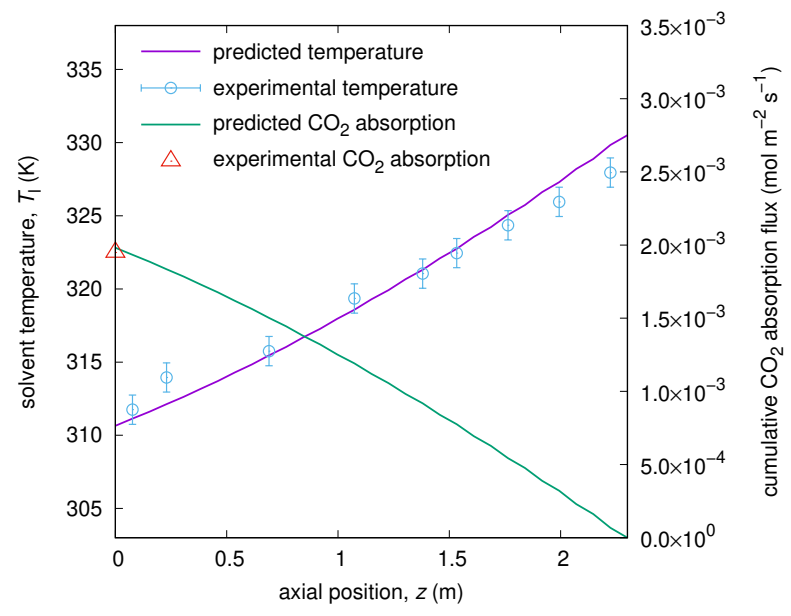

Figure 8: Comparison of solvent temperature profile against experimental data along the axis of the lab-scale module, and corresponding $\mathrm{CO}_{2}$ absorption rate. The gas inlet flowrate and $\mathrm{CO}_{2}$ content and the solvent inlet flowrate and $\mathrm{CO}_{2}$ loading were, respectively, $2 \mathrm{~kg} \mathrm{~h}^{-1}, 24 \mathrm{~mol} \%, 10 \mathrm{~L} \mathrm{~h}^{-1}$ and $0.22 \mathrm{~mol} \mathrm{~mol}^{-1}$.

$\mathrm{CO}_{2}$ solubility in the solvent; and (iii) a lower surface tension of the solvent that leads to higher wetting of the membrane. The marginal effect of the inlet gas flowrate on the $\mathrm{CO}_{2}$ absorption flux in the investigated range is correctly captured by the model (Fig. $7 \mathrm{~B}$ ), which confirms that the gas pressure drop in the tubes may be safely neglected. The beneficial effect of a higher solvent flowrate on the $\mathrm{CO}_{2}$ absorption flux likewise is correctly described by the model (Fig. 75). This effect is mainly attributed to the reduction in solvent temperature rise inside the module as the solvent flowrate increases, leading to a relatively higher liquid surface tension and reducing the membrane wetting in turn. In particular, this effect prevails over the pressure drop increase in the shell, which contributes to membrane wetting by increasing the transmembrane pressure along the fibers. The effect of a leaner amine creating a larger concentration gradient is also beneficial to the overall $\mathrm{CO}_{2}$ mass transfer.

It is seen from Fig. 8 that the predicted solvent temperature profile along the fiber length is in excellent agreement with the measured solvent temperature. This comparison provides a first validation of the assumption made in the energy balance modeling (Sec. 2.2), whereby the heat released from the $\mathrm{CO}_{2}$ absorption in amine solvent is much greater than the heat losses caused by the solvent evaporation (ca. $1 \mathrm{~K}$ ). Notice also that the temperature rise between the solvent inlet and outlet is significant (ca. $20 \mathrm{~K}$ ), yet no temperature bulge is observed in the center part of the MBC module, unlike the phenomenon often observed in conventional absorption towers. The predicted cumulative $\mathrm{CO} 2$ absorption flux is zero at the gas inlet $(z=L)$ and increases along the fiber axis. The $\mathrm{CO}_{2}$ absorption flux presents a slow decrease from the gas inlet to the gas outlet (negative curvature), which is expected since a higher $\mathrm{CO}_{2}$ concentration near the gas inlet enhances the mass transfer of $\mathrm{CO}_{2}$ through the membrane. Likewise, the temperature rise is higher near the gas inlet (positive curvature) due to more heat being released from the $\mathrm{CO}_{2}$ absorption in amine solvent. 


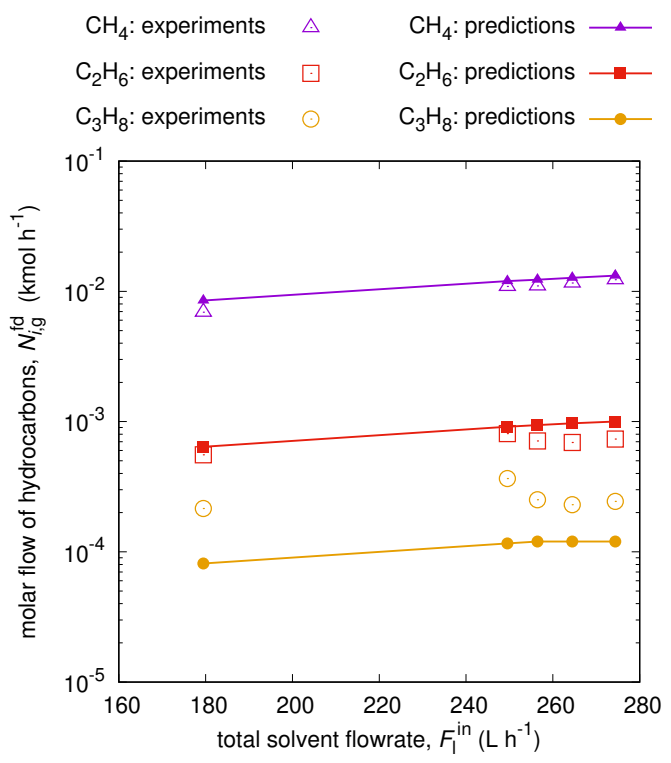

Figure 9: Comparison of predicted hydrocarbon molar flow in flashed gas against experimental data from the pilot plant. The gas inlet flowrate and $\mathrm{CO}_{2}$ content and the solvent inlet $\mathrm{CO}_{2}$ loading were, respectively, $75 \mathrm{~kg} \mathrm{~h}^{-1}, 5 \mathrm{~mol} \%$ and $0.01 \mathrm{~mol} \mathrm{~mol}^{-1}$.

\subsection{Experimental Model Verification: Pilot Setup}

Additional comparisons between measured and predicted $\mathrm{CO}_{2}$ absorption fluxes are presented in Fig. 7D-E for the pilot-scale MBC module, corresponding to a range of $\mathrm{CO}_{2}$ loadings and flowrates of amine solvent and gas flowrates and compositions. The flux predictions that were obtained using the regressed Henry's constant in Eq. 29] are again in excellent agreement with the experimental fluxes. But similar to the lab-scale module above, the fluxes computed using the semi-empirical correlation of Bensetiti et al. [35] overestimate the experimental fluxes by up to $10 \%$ under semi-lean operation. Both predicted fluxes nonetheless remain in close agreement under lean conditions (first experimental point on Fig.7P and all points on Fig.7F), where diffusive mass transfer is limiting over $\mathrm{CO}_{2}$ dissolution at the gas-liquid interface. Also in agreement with the lab-scale results, the $\mathrm{MBC}$ model correctly predicts that a higher $\mathrm{CO}_{2}$ loading at the solvent inlet is detrimental to the $\mathrm{CO}_{2}$ absorption flux (Fig.7D).

Experimental data corresponding to different $\mathrm{CO}_{2}$ concentrations in the $\mathrm{NG}$ feed and a lean amine solvent are shown in Fig. 7F. The MBC model correctly predicts the increase in $\mathrm{CO}_{2}$ absorption flux when the $\mathrm{CO}_{2}$ inlet concentration increases, as driven by a higher $\mathrm{CO}_{2}$ concentration in the fibers. The MBC model also predicts a very low degree of membrane wetting under lean operation, which corroborates the findings by Quek et al. [19] in a horizontal MBC module.

\subsection{Assessment of hydrocarbon loss in high-pressure MBC for natural gas sweetening}

Recall that the solvent outlet of the pilot-scale MBC module is directed to a flash drum (Fig. 3), where both the flow and composition of the flashed gas were monitored. A comparison between predicted and measured molar flowrates of light hydrocarbons in the flashed gas, which we denoted by $N_{i, \mathrm{~g}}^{\mathrm{fd}}$ with $i \in\left\{\mathrm{CH}_{4}, \mathrm{C}_{2} \mathrm{H}_{6}, \mathrm{C}_{3} \mathrm{H}_{8}\right\}$, is presented in Fig. 9 at different solvent 


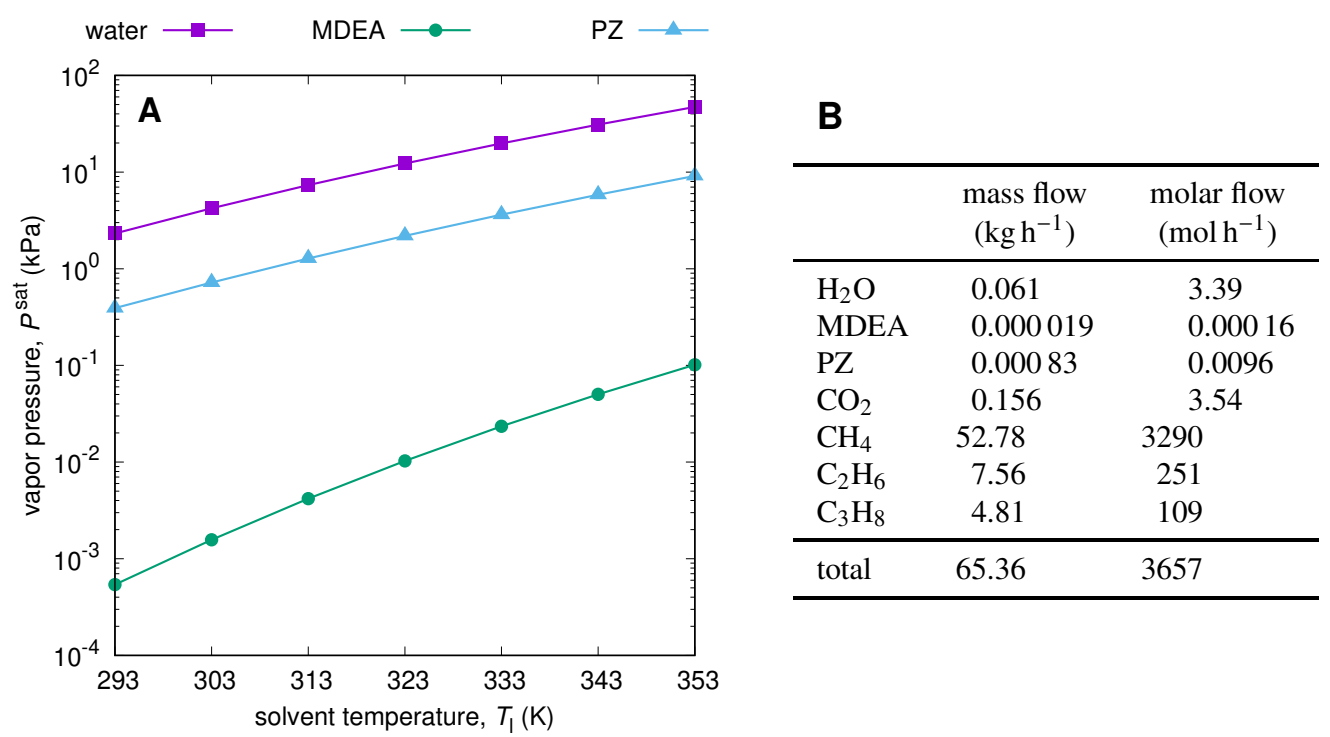

Figure 10: A: Vapour pressures of water, MDEA and PZ for solvent temperatures between 293-353 K. B: Predicted mass and molar flowrates in the treated gas stream, for a gas inlet flowrate and $\mathrm{CO}_{2}$ content and a solvent inlet flowrate and $\mathrm{CO}_{2}$ loading of, respectively, $75 \mathrm{~kg} \mathrm{~h}^{-1}, 5 \mathrm{~mol} \%, 270 \mathrm{~L} \mathrm{~h}^{-1}$ and $0.01 \mathrm{~mol} \mathrm{~mol}^{-1}$.

flowrates. All of the predicted molar flows of methane and ethane are within $15 \%$ of the measurements. Such a close agreement is remarkable and validates the assumption that the solvent is about saturated with hydrocarbons at the MBC outlet (Sec. 2.3). By contrast, the predicted molar

375 flows of propane underestimate the measurements by a factor of $2-4$, which could result from these flowrates being comparatively very small and more susceptible to experimental error. But overall, these results confirm that the proposed approach to modeling the hydrocarbon losses is completely suitable for use in a techno-economic assessment (see companion paper [29]).

The comparison in Fig.9 9 furthermore indicates that the methane losses are an order of magni380 tude greater than ethane and higher hydrocarbon losses. This was expected given that the natural gas processed by the pilot plant contains over $75 \mathrm{wt} \%$ of methane, and that methane has a higher solubility in amine than ethane and higher hydrocarbons (Fig. 6). Finally, increasing the solvent flowrate gives rise to a higher concentration gradient in the radial direction, thereby increasing the hydrocarbon losses, an effect that is correctly captured by the model.

\subsection{Assessment of solvent evaporative loss in high-pressure MBC for natural gas sweetening}

Little research has been conducted to date on evaporative amine losses in either atmospheric or high-pressure MBC. Herein, we use the simple evaporation modeling from Sec.2.2 to quantify these losses. The results tabulated in Fig. $10 \mathrm{~B}$ predict for the water loss to the treated gas to be greater by two orders of magnitude or more than the MDEA and PZ losses. This vast difference can be attributed to the composition of the solvent and the fact that the vapor pressures of water is much larger than those of MDEA and PZ in the temperature of interest (Fig. 10A). But recall that these predictions rely on the assumption that the treated gas is saturated with solvent. Although saturation may not be reached in practice due to the short gas residence time in the fibers, these predictions can nonetheless provide a worst-case scenario and be used in a techno-economic 
395 analysis; see, for instance, the process-wide assessment of MBC for natural gas sweetening in the companion paper [29].

Under the operating conditions of Fig. 10, the worst-case solvent loss is predicted to be about $0.03 \%$ of the total solvent fed to the pilot-scale MBC. The corresponding total amine loss (MDEA and PZ) with the treated gas amounts to $8 \mathrm{mg}$ per $\mathrm{Sm}^{3}$ of treated gas. Note that this prediction

400 compares favorably with the average loss of ca. $48 \mathrm{mg} \mathrm{Sm}^{-3}\left(3 \mathrm{lb} \mathrm{MMSCF}^{-1}\right)$ reported in the literature for conventional NG sweetening plants [37]. Also note that the corresponding energy expended from solvent evaporation is less than $1 \%$ of the heat produced by the $\mathrm{CO}_{2}$ absorption reactions. This comparison thereby provides another confirmation that solvent evaporation has a minimal impact on the solvent temperature at high pressure, and may even be omitted from the energy balance (Sec. 2.2.

The benefit of high-pressure MBC operation in regards of solvent evaporative losses is clear insofar as Raoult's law (Eq. 20) remains applicable, since the molar fraction of solvent in the treated gas is inversely proportional to the gas pressure. In comparison to the scenario in Fig. $10 \mathrm{~B}$, one could therefore expect for the solvent evaporative losses to be about 50-times larger in an

410 atmospheric-pressure $\mathrm{MBC}$; e.g., for post-combustion $\mathrm{CO}_{2}$ capture [6, 7]. In such $\mathrm{MBC}$ applications where the rate of evaporation is indeed much higher, the use of Raoult's law may become questionable, calling for a more detailed modeling approach based on distributed mass and energy balances instead.

\section{Conclusions}

This paper has presented a predictive mathematical model of high-pressure MBC, with a view to developing a plant-wide model of MBC-based natural gas sweetening. Our model is the first to enable quantitative predictions of the $\mathrm{CO}_{2}$ absorption fluxes and solvent temperature profile inside the $\mathrm{MBC}$, under both lean or semi-lean solvent loading. It furthermore quantifies the absorptive losses of light hydrocarbons (methane, ethane and propane) with the amine solvent,

420 and the evaporative losses of water and amines to the treated gas. The amount of hydrocarbons that can be recovered in a downstream flash drum in order to minimize product loss is important from a techno-economic standpoint, and so is the ability to predict the solvent evaporation rate and its composition in order to determine and price the amount of solvent make-up in a full-scale MBC process.

425 A verification of the model has been conducted with experimental data from both a lab-scale module and a pilot-scale module, using an improved membrane fiber compared to Quek et al. [19]. A close agreement between predicted and measured $\mathrm{CO}_{2}$ absorption fluxes was obtained for a range of solvent flowrates and $\mathrm{CO}_{2}$ loadings as well as gas flowrates and compositions in both the lab- and pilot-scale modules. In particular, our results establish the need to model

430 the effect of $\mathrm{CO}_{2}$ loading in amine solvent on the $\mathrm{CO}_{2}$ solubility for accurate predictions of the $\mathrm{CO}_{2}$ absorption fluxes in MBC. A good agreement was also noted between the predicted and measured solvent temperature profiles in the lab-scale module, confirming that the heat losses by solvent evaporation only have a small effect on the solvent outlet temperature in high-pressure MBC. By comparing the predicted and measured flowrates of light hydrocarbons in the flashed gas from the rich amine drum of the pilot setup, we could furthermore verify our assumption that the solvent is about saturated with hydrocarbons at the MBC outlet. Lastly, we investigated the solvent evaporative losses under the assumption that the treated gas is saturated with solvent. Our analysis revealed that the worst-case solvent evaporation rate in the pilot setup should consist of a very small fraction of the solvent feed rate, therefore not affecting the model predictions. We 
440 also established that the evaporative water losses should vastly prevail over the losses of MDEA and PZ, and we noted the benefits of high-pressure MBC operation in terms of minimizing the solvent losses.

Moving forward, we are now in a position to integrate the MBC model with a solvent regeneration unit for the development of an MBC-based natural gas sweetening process. Plant-wide

445 models can empower the analysis of different conceptual designs, including various absorptiondesorption configurations and operational decisions for process scale-up and eventually processwide economic assessment. Such a process integration and plant-wide assessment is conducted in the companion paper [29].

Acknowledgments. The authors gratefully acknowledge PETRONAS for financial support and ${ }_{450}$ for providing the experimental data through the PETRONAS Centre for Engineering of Multiphase Systems at Imperial College London.

\section{References}

[1] S. Paul, A. K. Ghoshal, and B. Mandal. Removal of $\mathrm{CO}_{2}$ by single and blended aqueous alkanolamine solvents in hollow-fiber membrane contactor: Modeling and simulation. Industrial E Engineering Chemistry Research, 46(8): 2576-2588, 2007. doi: 10.1021/ie061476f.

[2] N. MacDowell, N. Florin, A. Buchard, J. Hallett, A. Galindo, G. Jackson, C. S. Adjiman, C. K. Williams, N. Shah, and P. Fennell. An overview of $\mathrm{CO}_{2}$ capture technologies. Energy E Environmental Science, 3(11):1645-1669, 2010. doi: 10.1039/c004106h.

[3] A. Gabelman and S.-T. Hwang. Hollow fiber membrane contactors. Journal of Membrane Science, 159(1-2): 61-106, 1999. doi: 10.1016/S0376-7388(99)00040-X.

[4] X. He and M. B. Hägg. Membranes for environmentally friendly energy processes. Membranes, 2(4):706-726, 2012. doi: 10.3390/membranes2040706.

[5] H. A. Rangwala. Absorption of carbon dioxide into aqueous solutions using hollow fiber membrane contactors. Journal of Membrane Science, 112(2):229-240, 1996. doi: 10.1016/0376-7388(95)00293-6.

[6] E. Favre. Membrane processes and postcombustion carbon dioxide capture: Challenges and prospects. Chemical Engineering Journal, 171(3):782-793, 2011. doi: 10.1016/j.cej.2011.01.010.

[7] A. Mansourizadeh and A. F. Ismail. Hollow fiber gas-liquid membrane contactors for acid gas capture: A review. Journal of Hazardous Materials, 171:38-53, 2009. doi: 10.1016/j.jhazmat.2009.06.026.

[8] K. A. Hoff and H. F. Svendsen. Membrane contactors for $\mathrm{CO}_{2}$ absorption - Application, modeling and mass transfer effects. Chemical Engineering Science, 116:331-341, 2014. doi: 10.1016/j.ces.2014.05.001.

[9] K. A. Hoff and H. F. Svendsen. $\mathrm{CO}_{2}$ absorption with membrane contactors vs. packed absorbers - Challenges and opportunities in post combustion capture and natural gas sweetening. Energy Procedia, 37(1876):952-960, 2013. doi: 10.1016/j.egypro.2013.05.190.

[10] V. C. Quek, A. A. Azmil, Z. P. Chan, Y. Cao, G. Kang, M. Li, and J. Jia. Process and system for treating natural

475 gas feedstock, WO Patent Application PCT/CN2013/000,840, 2015.
[11] S. Zhou and H. Meyer. Sweetening of natural gas by membrane contactor, WO Patent Application PCT/US2014/022,290, 2014.

[12] R. Wang, H. Y. Zhang, P. H. M. Feron, and D. T. Liang. Influence of membrane wetting on $\mathrm{CO}_{2}$ capture in microporous hollow fiber membrane contactors. Separation $\mathcal{E}$ Purification Technology, 46(1-2):33-40, 2005. doi: 10.1016/j.seppur.2005.04.007.

[13] J. G. Lu, Y. F. Zheng, and M. D. Cheng. Wetting mechanism in mass transfer process of hydrophobic membrane gas absorption. Journal of Membrane Science, 308(1-2):180-190, 2008. doi: 10.1016/j.memsci.2007.09.051.

[14] S. Mosadegh-Sedghi, D. Rodrigue, J. Brisson, and M. C. Iliuta. Wetting phenomenon in membrane contactors causes and prevention. Journal of Membrane Science, 452:332-353, 2012. doi: 10.1016/j.memsci.2013.09.055.

485 [15] W. Rongwong, C. Fan, Z. Liang, Z. Rui, R. O. Idem, and P. Tontiwachwuthikul. Investigation of the effects of operating parameters on the local mass transfer coefficient and membrane wetting in a membrane gas absorption process. Journal of Membrane Science, 490:236-246, 2015. doi: 10.1016/j.memsci.2015.04.071.

[16] E. Chabanon, D. Roizard, and E. Favre. Modeling strategies of membrane contactors for post-combustion carbon capture: A critical comparative study. Chemical Engineering Science, 87:393-407, 2013. doi: 10.1016/j.ces.2012. 09.011. 
[17] S. Boributh, S. Assabumrungrat, N. Laosiripojana, and R. Jiraratananon. A modeling study on the effects of membrane characteristics and operating parameters on physical absorption of $\mathrm{CO}_{2}$ by hollow fiber membrane contactor. Journal of Membrane Science, 380(1-2):21-33, 2011. doi: 10.1016/j.memsci.2011.06.029.

[18] N. Goyal, S. Suman, and S. K. Gupta. Mathematical modeling of $\mathrm{CO}_{2}$ separation from gaseous-mixture using a hollow-fiber membrane module: Physical mechanism and influence of partial-wetting. Journal of Membrane Science, 474:64-82, 2015. doi: 10.1016/j.memsci.2014.09.036.

[19] V. C. Quek, N. Shah, and B. Chachuat. Modeling for design and operation of high-pressure membrane contactors in natural gas sweetening. Chemical Engineering Research $\mathcal{E}$ Design, 132:1005-1019, 2018. doi: 10.1016/j.cherd. 2018.01.033

500 [20] N. Ghasem, M. Al-Marzouqi, and N. Abdul Rahim. Modeling of $\mathrm{CO}_{2}$ absorption in a membrane contactor considering solvent evaporation. Separation E Purification Technology, 110:1-10, 2013. doi: 10.1016/j.seppur.2013.03. 008.

[21] N. A. Al-Baghli, S. A. Pruess, V. F. Yesavage, and M. S. Selim. A rate-based model for the design of gas absorbers for the removal of $\mathrm{CO}_{2}$ and $\mathrm{H}_{2} \mathrm{~S}$ using aqueous solutions of MEA and DEA. Fluid Phase Equilibria, 185(1-2): 31-43, 2001. doi: 10.1016/S0378-3812(01)00454-X.

[22] H. M. Kvamsdal and G. T. Rochelle. Effects of the temperature bulge in $\mathrm{CO}_{2}$ absorption from flue gas by aqueous monoethanolamine. Industrial E Engineering Chemistry Research, 47(3):867-875, 2008. doi: 10.1021/ie061651s.

[23] Gas Processors Suppliers Association. Section 21: Hydrocarbon treating. In GPSA Engineering Data Book. 12th edition, 2004.

[24] L. Addington and C. Ness. An evaluation of general "rules of thumb" in amine sweetening unit design and operation. GPA Annual Convention Proceedings, 1:119-135, 2010.

[25] J. J. Carroll, J. Maddocks, and A. E. Mather. The solubility of hydrocarbons in amine solutions. Laurance Reid Gas Conditioning Conference, pages 44-64, 1998.

[26] F. A. Sánchez, T. M. Soria, S. Pereda, A. H. Mohammadi, D. Richon, and E. A. Brignole. Phase behavior modeling of alkylamine+water mixtures and prediction of alkane solubilities in alkanolamine aqueous solutions with group contribution with association equation of state. Industrial $\mathcal{E}$ Engineering Chemistry Research, 49(15):7085-7092, 2010. doi: 10.1021/ie100421m

[27] N. Hatcher, C. Jones, and R. Weiland. Solubility of hydrocarbons and light ends in amines. Petroleum Technology Quarterly, GAS, 2013.

520 [28] G. Kang, Z. P. Chan, S. B. M. Saleh, and Y. Cao. Removal of high concentration $\mathrm{CO}_{2}$ from natural gas using high pressure membrane contactors. International Journal of Greenhouse Gas Control, 60:1-9, 2017. doi: 10.1016/j ijggc.2017.03.003

[29] V. C. Quek, N. Shah, and B. Chachuat. Plant-wide assessment of high-pressure membrane contactors in natura gas sweetening - Part II: Process analysis. Submitted for publication, 2020.

525 [30] J. Happel. Viscous flow relative to arrays of cylinders. AIChE Journal, 5(2):174-177, 1959. doi: 10.1002/aic. 690050211.

[31] S. B. Iversen, V. K. Bhatia, K. Dam-Johansen, and G. Jonsson. Characterization of microporous membranes for use in membrane contactors. Journal of Membrane Science, 130(1-2):205-217, 1997. doi: 10.1016/S0376-7388(97) 00026-4.

32] A. L. Zydney, P. Aimar, M. Meireles, J. M. Pimbley, and G. Belfort. Use of the log-normal probability density function to analyze membrane pore size distributions: Functional forms and discrepancies. Journal of Membrane Science, 91(3):293-298, 1994. doi: 10.1016/0376-7388(94)80090-1.

[33] H. Kreulen, C. A. Smolders, G. F. Versteeg, and W. P. M. Van Swaaij. Determination of mass transfer rates in wetted and non-wetted microporous membranes. Chemical Engineering Science, 48(11):2093-2102, 1993. ISSN 0009-2509. doi: 10.1016/0009-2509(93)80084-4.

[34] M. K. Park and O. C. Sandall. Solubility of carbon dioxide and nitrous oxide in 50 mass \% methyldiethanolamine. Journal of Chemical E Engineering Data, 46(1):166-168, 2001. doi: 10.1021/je000190t.

[35] Z. Bensetiti, I. Iliuta, F. Larachi, and B. P. A Grandjean. Solubility of nitrous oxide in amine aqueous solutions. Industrial E Engineering Chemistry Research, 38(1):328-332, 1999. doi: 10.1021/je990253b.

36] M. Oh and C.C. Pantelides. A modelling and simulation language for combined lumped and distributed parameter systems. Computers $\mathcal{E}$ Chemical Engineering, 20(6-7):611-633, 1996. doi: 10.1016/0098-1354(95)00196-4

[37] E. Teletzke and B. Madhyani. Minimise amine losses in gas and liquid treating. Petroleum Technology Quaterly Gas, pages 35-45, 2018.

[38] J.-J. Ko and M.-H. Li. Kinetics of absorption of carbon dioxide into solutions of N -methyldiethanolamine+water. Chemical Engineering Science, 55(19):4139-4147, 2000. doi: 10.1016/S0009-2509(00)00079-8.

[39] W. C. Sun, C. B. Yong, and M. H. Li. Kinetics of the absorption of carbon dioxide into mixed aqueous solutions of 2-amino-2-methyl-1-propanol and piperazine. Chemical Engineering Science, 60(2):503-516, 2005. doi: 10.1016/ j.ces.2004.08.012.

[40] J. G. Lu, Y. F. Zheng, M. D. Cheng, and L. J. Wang. Effects of activators on mass-transfer enhancement in a hollow 
fiber contactor using activated alkanolamine solutions. Journal of Membrane Science, 289(1-2):138-149, 2007. doi: 10.1016/j.memsci.2006.11.042.

[41] G. F. Versteeg and W. P. M. Van-Swaaij. Solubility and diffusivity of acid gases $\left(\mathrm{CO}_{2}, \mathrm{~N}_{2} \mathrm{O}\right)$ in aqueous alkanilamine solutions. Journal of Chemical $\mathcal{F}$ Engineering Data, 33(1):29-34, 1988. doi: 10.1021/je00051a011.

[42] Z. Wang, M. Fang, H. Yu, Q. Ma, and Z. Luo. Modeling of $\mathrm{CO}_{2}$ stripping in a hollow fiber membrane contactor for $\mathrm{CO}_{2}$ capture. Energy $\mathcal{E}$ Fuels, 27(11):6887-6898, 2013. doi: 10.1021/ef401488c.

[43] B. P. Mandal, A. K. Biswas, and S. S. Bandyopadhyay. Absorption of carbon dioxide into aqueous blends of 2 amino-2-methyl-1-propanol and diethanolamine. Chemical Engineering Science, 58(18):4137-4144, 2003. doi: 10.1016/S0009-2509(03)00280-X.

[44] E. L. Cussler. Diffusion: Mass Transfer in Fluid Systems. Cambridge University Press, New York, third edition, 2009.

[45] R. B. Bird, E. N. Lightfoot, and W. E. Stewart. Transport Phenomena. John Wiley \& Sons, New York, second edition, 2002.

\section{Appendix A. Transport and Reaction Kinetic Correlations}

- Macroscopic reaction rates between the $\mathrm{CO}_{2}$ and the amine solvent were assumed to follow mass-action kinetics,

$$
\begin{aligned}
R_{\mathrm{CO}_{2}} & =-k_{\mathrm{MDEA}} C_{\mathrm{CO}_{2}} C_{\mathrm{MDEA}}-k_{\mathrm{PZ}} C_{\mathrm{CO}_{2}} C_{\mathrm{PZ}} \\
R_{\mathrm{MDEA}} & =-k_{\mathrm{MDEA}} C_{\mathrm{CO}_{2}} C_{\mathrm{MDEA}} \\
R_{\mathrm{PZ}} & =-k_{\mathrm{PZ}} C_{\mathrm{CO}_{2}} C_{\mathrm{PZ}}
\end{aligned}
$$

with the reaction rate constants given by [38-40]

$$
\begin{aligned}
k_{\mathrm{MDEA}} & =4.01 \times 10^{5} \exp \left(-\frac{5400}{T_{1}}\right) \\
k_{\mathrm{PZ}} & =4.49 \times 10^{9} \exp \left(-\frac{5712}{T_{1}}\right)
\end{aligned}
$$

- The Henry's constant for $\mathrm{CO}_{2}$ in amine solvent was estimated using an $\mathrm{N}_{2} \mathrm{O}$ analogy [41. 42],

$$
H_{\mathrm{CO}_{2}, 1}=H_{\mathrm{N}_{2} \mathrm{O}, 1} \frac{H_{\mathrm{CO}_{2}, \mathrm{H}_{2} \mathrm{O}}}{H_{\mathrm{N}_{2} \mathrm{O}, \mathrm{H}_{2} \mathrm{O}}}
$$

where the Henry's constant of $\mathrm{N}_{2} \mathrm{O}$ in amine solvent was regressed from experimental data (Eq. 29); and both Henry's constants for $\mathrm{N}_{2} \mathrm{O}$ and $\mathrm{CO}_{2}$ in water were taken as [41]

$$
\begin{aligned}
& H_{\mathrm{CO}_{2}, \mathrm{H}_{2} \mathrm{O}}=2.82 \times 10^{6} \exp \left(-\frac{2044}{T_{1}}\right) \\
& H_{\mathrm{N}_{2} \mathrm{O}, \mathrm{H}_{2} \mathrm{O}}=8.55 \times 10^{6} \exp \left(-\frac{2284}{T_{1}}\right)
\end{aligned}
$$

- The diffusivity of $\mathrm{CO}_{2}$ in the amine solvent was also estimated using an $\mathrm{N}_{2} \mathrm{O}$ analogy [41]

$$
D_{\mathrm{CO}_{2}, \mathrm{l}}=D_{\mathrm{N}_{2} \mathrm{O}, \mathrm{l}} \frac{D_{\mathrm{CO}_{2}, \mathrm{H}_{2} \mathrm{O}}}{D_{\mathrm{N}_{2} \mathrm{O}, \mathrm{H}_{2} \mathrm{O}}}
$$


with the diffusivities of $\mathrm{CO}_{2}$ and $\mathrm{N}_{2} \mathrm{O}$ in water given by

$$
\begin{aligned}
& D_{\mathrm{CO}_{2}, \mathrm{H}_{2} \mathrm{O}}=2.35 \times 10^{-6} \exp \left(-\frac{2119}{T_{1}}\right) \\
& D_{\mathrm{N}_{2} \mathrm{O}, \mathrm{H}_{2} \mathrm{O}}=5.07 \times 10^{-6} \exp \left(-\frac{2371}{T_{1}}\right)
\end{aligned}
$$

The diffusivity of $\mathrm{N}_{2} \mathrm{O}$ in amine solvent was estimated using the modified Stokes-Einstein relation [42, 43]

$$
D_{\mathrm{N}_{2} \mathrm{O}, 1}=D_{\mathrm{N}_{2} \mathrm{O}, \mathrm{H}_{2} \mathrm{O}}\left(\frac{\mu_{\mathrm{H}_{2} \mathrm{O}}}{\mu_{1}}\right)^{0.6}
$$

- The temperature-corrected diffusivities of MDEA and PZ in the solvent were estimated using the modified Stokes-Einstein relation [43]

$$
\begin{aligned}
D_{\mathrm{MDEA}, 1} & =D_{\mathrm{MDEA}, \mathrm{H}_{2} \mathrm{O}} \frac{T_{1}}{273}\left(\frac{\mu_{\mathrm{H}_{2} \mathrm{O}}}{\mu_{1}}\right)^{0.6} \\
D_{\mathrm{PZ}, 1} & =D_{\mathrm{PZ}, \mathrm{H}_{2} \mathrm{O}} \frac{T_{1}}{273}\left(\frac{\mu_{\mathrm{H}_{2} \mathrm{O}}}{\mu_{1}}\right)^{0.6}
\end{aligned}
$$

- The diffusivity of $\mathrm{CO}_{2}$ in the natural gas was estimated from empirical correlations based on kinetic gas theory [44, 45]

$$
D_{\mathrm{CO}_{2}, \mathrm{~g}}=\frac{T_{\mathrm{g}}^{1.75}}{P_{\mathrm{g}}} \frac{\sqrt{\frac{1}{M W_{\mathrm{CO}_{2}}}+\frac{1}{M W_{\mathrm{NG}}}}}{\left(\sqrt[3]{\sum V_{\mathrm{CO}_{2}}}+\sqrt[3]{\sum V_{\mathrm{NG}}}\right)^{2}}
$$

with the sums of the diffusion volume for $\mathrm{CO}_{2}$ and natural gas given by $\sum V_{\mathrm{CO}_{2}}=26.9$ and $\sum V_{\mathrm{NG}}=24.4$. 


\begin{tabular}{|c|c|c|c|}
\hline \multicolumn{4}{|c|}{ Nomenclature } \\
\hline \multicolumn{2}{|c|}{ Acronyms } & $f$ & fraction or loading, $\left(\mathrm{mol} \mathrm{mol}^{-1}\right)$ \\
\hline HFM & hollow-fiber membrane & $H$ & Henry's constant, $\left(\mathrm{m}^{3} \mathrm{~Pa} \mathrm{~mol}^{-1}\right)$ \\
\hline MBC & membrane contactor & $L$ & length of fiber, (m) \\
\hline MDEA & methyldiethanolamine & $M$ & mass flowrate, $\left(\mathrm{kg} \mathrm{s}^{-1}\right)$ \\
\hline NG & natural gas & $M W$ & molar mass, $\left(\mathrm{kg} \mathrm{mol}^{-1}\right)$ \\
\hline PSD & pore-size distribution & $N$ & molar flowrate, $\left(\mathrm{mol} \mathrm{s}^{-1}\right)$ \\
\hline PTFE & polytetrafluoroethylene & $n_{\mathrm{f}}$ & number of fibers in module, $(-)$ \\
\hline $\mathrm{PZ}$ & piperazine & $P$ & pressure, $(\mathrm{Pa})$ \\
\hline \multicolumn{2}{|c|}{ Main Symbols } & $R$ & gas constant, $\left(=8.314 \mathrm{~J} \mathrm{~mol}^{-1} \mathrm{~K}^{-1}\right)$ \\
\hline$\Delta H^{\mathrm{rxn}}$ & specific heat of reaction, $\left(\mathrm{J} \mathrm{mol}^{-1}\right)$ & $r$ & radial position, $(\mathrm{m})$ \\
\hline$\Delta H^{\mathrm{vap}}$ & $\begin{array}{l}\text { specific heat of vaporization, } \\
\left(\mathrm{J} \mathrm{mol}^{-1}\right)\end{array}$ & $\begin{array}{l}r_{1} \\
r_{2}\end{array}$ & $\begin{array}{l}\text { inner radius of fiber, }(\mathrm{m}) \\
\text { outer radius of fiber, }(\mathrm{m})\end{array}$ \\
\hline $\begin{array}{l}\Delta P \\
\delta\end{array}$ & $\begin{array}{l}\text { transmembrane pressure, }(\mathrm{Pa}) \\
\text { pore radius, }(\mu \mathrm{m})\end{array}$ & $r_{3}$ & $\begin{array}{l}\text { outer radius of virtual cylindrical } \\
\text { domain around each fiber, }(\mathrm{m})\end{array}$ \\
\hline$\delta_{\mathrm{w}}$ & critical pore radius, $(\mu \mathrm{m})$ & $R_{i}$ & reaction rate of species $i,\left(\mathrm{~mol} \mathrm{~s}^{-1}\right)$ \\
\hline$\eta$ & packing density of module, $(-)$ & $r_{\mathrm{m}}$ & inner radius of module, $(\mathrm{m})$ \\
\hline$\gamma$ & surface tension, $\left(\mathrm{N} \mathrm{m}^{-1}\right)$ & $r_{\mathrm{w}}$ & wetted radius, (m) \\
\hline$\mu$ & dynamic viscosity, $\left(\mathrm{kg} \mathrm{m}^{-1} \mathrm{~s}^{-1}\right)$ & $T$ & temperature, $(\mathrm{K})$ \\
\hline$\mu_{\delta}$ & mean pore radius, $(\mu \mathrm{m})$ & $v$ & velocity, $\left(\mathrm{m} \mathrm{s}^{-1}\right)$ \\
\hline$\omega$ & wetting ratio, $(-)$ & $x$ & mass fraction, $(-)$ \\
\hline$\Phi$ & $\mathrm{CO}_{2}$ absorption flux, $\left(\mathrm{mol} \mathrm{m}^{-2} \mathrm{~s}^{-1}\right)$ & $y$ & molar fraction, $(-)$ \\
\hline$\rho$ & density, $\left(\mathrm{kg} \mathrm{m}^{-3}\right)$ & $Z$ & compressibility factor, $(-)$ \\
\hline$\sigma_{\delta}$ & pore standard deviation, $(\mu \mathrm{m})$ & $z$ & axial position, $(\mathrm{m})$ \\
\hline$\tau$ & tortuosity, $(-)$ & Subsc & ipts and Superscripts \\
\hline$\theta$ & contact angle, $\left({ }^{\circ}\right)$ & $\overline{(\cdot)}$ & averaged quantity \\
\hline$\varepsilon$ & porosity, (-) & fd & at flash drum outlet \\
\hline$\varphi$ & pore size distribution, (m) & in & at inlet \\
\hline$A_{\mathrm{m}}$ & membrane area, $\left(\mathrm{m}^{2}\right)$ & $\max$ & maximal value \\
\hline$C$ & molar concentration, $\left(\mathrm{mol} \mathrm{m}^{-3}\right)$ & out & at outlet \\
\hline$c_{P}$ & specific heat capacity of solvent at & $\mathrm{g}$ & in gas phase \\
\hline & constant pressure, $\left(\mathrm{J} \mathrm{kg}^{-1} \mathrm{~K}^{-1}\right)$ & 1 & in liquid phase \\
\hline$D$ & diffusivity, $\left(\mathrm{m}^{2} \mathrm{~s}^{-1}\right)$ & sat & at saturation \\
\hline$F$ & volumetric flowrate, $\left(\mathrm{m}^{3} \mathrm{~s}^{-1}\right)$ & sol & solvent \\
\hline
\end{tabular}

